Cochrane Database of Systematic Reviews

\title{
Use of plastic adhesive drapes during surgery for preventing surgical site infection (Review)
}

Webster J, Alghamdi A

Webster J, Alghamdi A.

Use of plastic adhesive drapes during surgery for preventing surgical site infection.

Cochrane Database of Systematic Reviews 2015, Issue 4. Art. No.: CD006353.

DOI: 10.1002/14651858.CD006353.pub4.

www.cochranelibrary.com 
TABLE OF CONTENTS

ABSTRACT 1

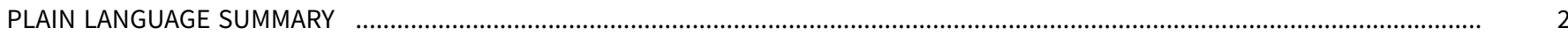

SUMMARY OF FINDINGS

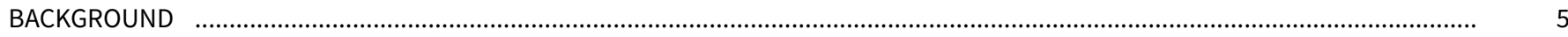

OBJECTIVES

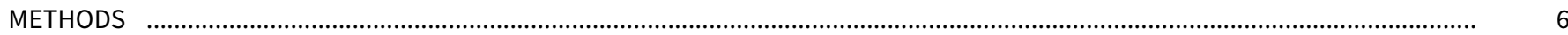

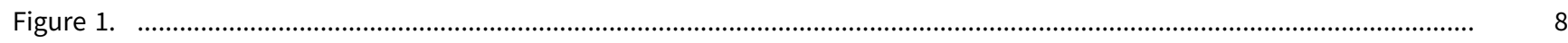

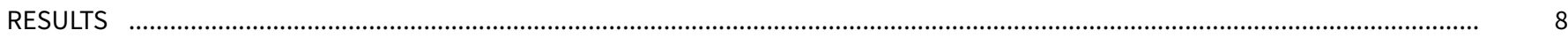

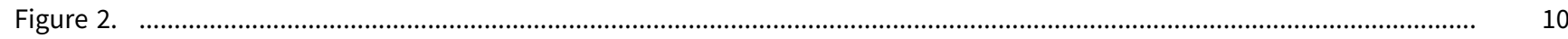

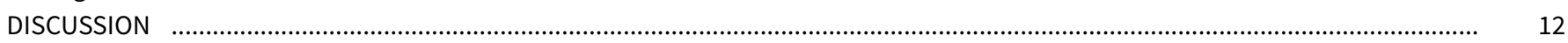

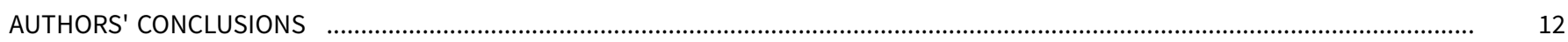

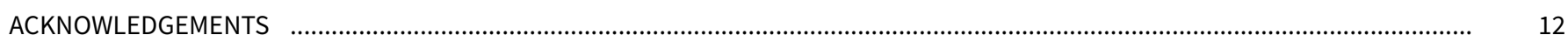

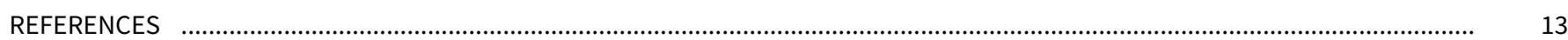

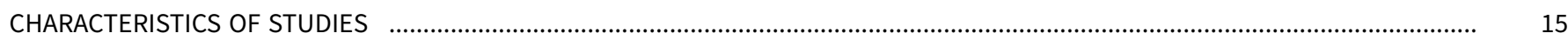

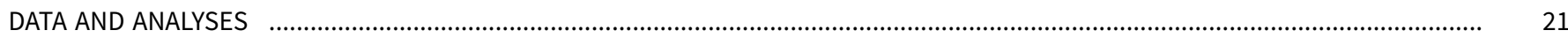

Analysis 1.1. Comparison 1 Adhesive drapes versus no adhesive drapes, Outcome 1 Surgical site infection (all wound 21 classifications).

Analysis 1.2. Comparison 1 Adhesive drapes versus no adhesive drapes, Outcome 2 Surgical site infection (by wound 22 classification).

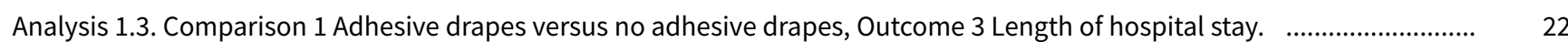

Analysis 2.1. Comparison 2 lodine-impregnated adhesive drapes versus no adhesive drapes, Outcome 1 Surgical site infection. 23

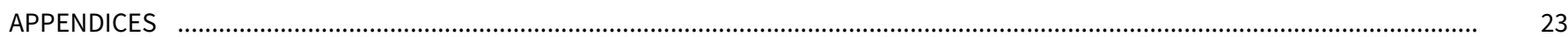

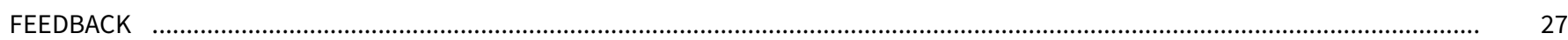

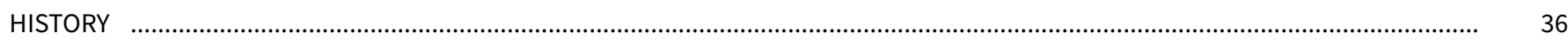

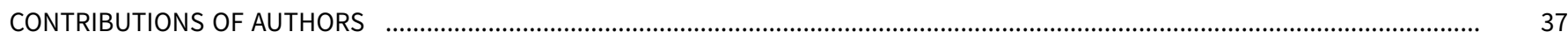

DECLARATIONS OF INTEREST

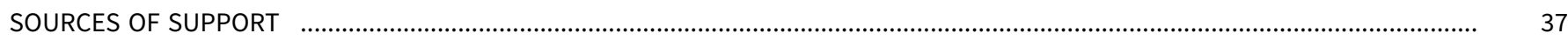

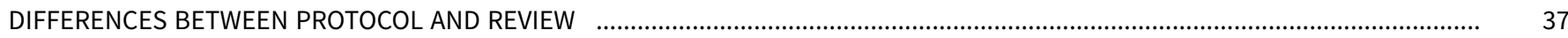

INDEX TERMS 
[Intervention Review]

\title{
Use of plastic adhesive drapes during surgery for preventing surgical site infection
}

Joan Webster1,2,3, Abdullah Alghamdi4

1 National Centre of Research Excellence in Nursing, Centre for Health Practice Innovation, Menzies Health Institute Queensland, Griffith University, Brisbane, Australia. ${ }^{2}$ School of Nursing and Midwifery, The University of Queensland, Brisbane, Australia. ${ }^{3} \mathrm{Nursing}$ and Midwifery Research Centre, Royal Brisbane and Women's Hospital, Herston, Australia. ${ }^{4}$ Department of Surgery, St Michael's Hospital, University of Toronto, Toronto, Canada

Contact: Joan Webster, Nursing and Midwifery Research Centre, Royal Brisbane and Women's Hospital, Butterfield Street, Herston, Queensland, 4029, Australia.wigan1943@bigpond.com, wigan1943@bigpond.com.

Editorial group: Cochrane Wounds Group.

Publication status and date: Edited (no change to conclusions), published in Issue 6, 2019.

Citation: Webster J, Alghamdi A. Use of plastic adhesive drapes during surgery for preventing surgical site infection. Cochrane Database of Systematic Reviews 2015, Issue 4. Art. No.: CD006353. DOI: 10.1002/14651858.CD006353.pub4.

Copyright $(2019$ The Cochrane Collaboration. Published by John Wiley \& Sons, Ltd.

\begin{abstract}
A B S T R A C T

\section{Background}

Surgical site infection has been estimated to occur in about $15 \%$ of clean surgery and $30 \%$ of contaminated surgery cases. Using plastic adhesive drapes to protect the wound from organisms that may be present on the surrounding skin during surgery is one strategy used to prevent surgical site infection. Results from non-randomised studies have produced conflicting results about the efficacy of this approach. A systematic review was required to guide clinical practice.
\end{abstract}

\section{Objectives}

To assess the effect of adhesive drapes used during surgery on surgical site infection, cost, mortality and morbidity.

\section{Search methods}

For this fourth update we searched the Cochrane Wounds Group Specialised Register (searched 4th March 2015); the Cochrane Central Register of Controlled Trials (CENTRAL) (The Cochrane Library 2015, Issue 2); Ovid MEDLINE (2012 to 3rd March 2015); Ovid MEDLINE (InProcess \& Other Non-Indexed Citations, 2012 to 3rd March 2015); Ovid EMBASE (2012 to 3rd March 2015); and EBSCO CINAHL (2012 to 4th March 2015).

\section{Selection criteria}

Randomised controlled trials comparing any plastic adhesive drape with no plastic adhesive drape, used alone or in combination with woven (material) drapes or disposable (paper) drapes, in patients undergoing any type of surgery. Ring drapes were excluded.

\section{Data collection and analysis}

Two review authors independently selected and assessed studies for trial quality and both independently extracted data. We contacted study authors for additional information.

\section{Main results}

We identified no new studies for this fourth update. The review includes five studies involving 3082 participants comparing plastic adhesive drapes with no drapes and two studies involving 1113 participants comparing iodine-impregnated adhesive drapes with no drapes. A significantly higher proportion of patients in the adhesive drape group developed a surgical site infection when compared with no drapes (risk ratio (RR) 1.23, 95\% confidence interval $(\mathrm{Cl}) 1.02$ to $1.48, \mathrm{P}=0.03$ ). lodine-impregnated adhesive drapes had no effect on the surgical 
site infection rate (RR 1.03, $95 \% \mathrm{Cl} 0.06$ to $1.66, \mathrm{P}=0.89)$. Length of hospital stay was similar in the adhesive drape and non-adhesive drape groups.

\section{Authors' conclusions}

There was no evidence from the seven trials that plastic adhesive drapes reduce surgical site infection rates, and some evidence that they increase infection rates. Further trials may be justified, using blinded outcome assessment to examine the effect of adhesive drapes on surgical site infection, based on different wound classifications.

\section{PLAIN LANGUAGE SUMMARY}

\section{Use of plastic adhesive drapes during surgery for preventing surgical site infection}

Following surgery, up to $30 \%$ of wounds may become infected. This complication of surgery may cause distress for the patient and lead to higher treatment costs. Many interventions have been designed to reduce postoperative infections. One of these is the use of a drape which adheres to the skin, and through which the surgeon cuts. It is thought that adhesive drapes prevent germs (which may be on the skin) from entering the open wound. This updated review of over 4000 patients, in seven separate trials could find no evidence that adhesive drapes reduce surgical site infection rates, and some evidence that they may increase infection rates. 
SUMMARY OF FINDINGS

\section{Summary of findings for the main comparison.}

Adhesive drapes compared with no adhesive drapes for preventing surgical site infection

Patient or population: Patients undergoing surgery

Settings: Hospital

Intervention: Adhesive drapes

Comparison: No adhesive drapes

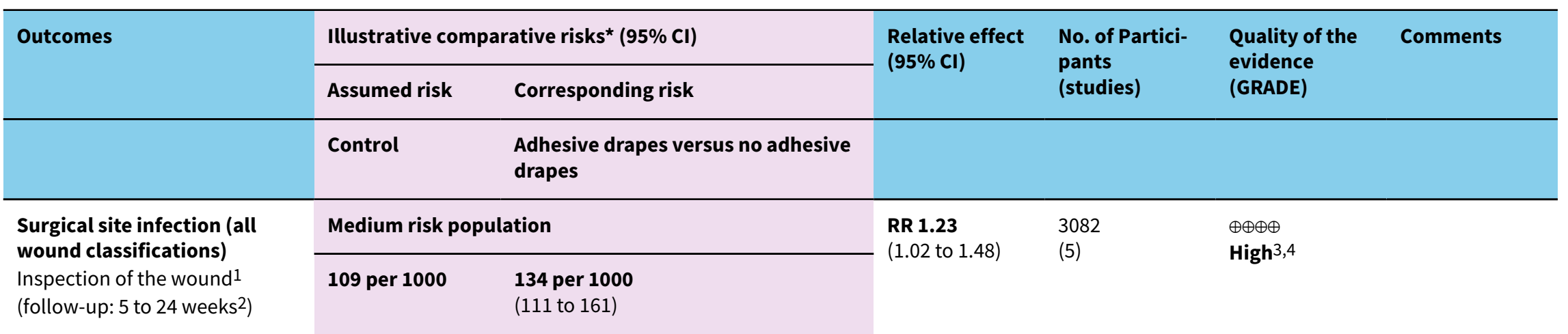

*The basis for the assumed risk (e.g. the median control group risk across studies) is provided in footnotes. The corresponding risk (and its $95 \% \mathrm{Cl}$ ) is based on the assumed risk in the comparison group and the relative effect of the intervention (and its $95 \% \mathrm{Cl}$ ).

Cl: Confidence interval; RR: Risk ratio

GRADE Working Group grades of evidence

High quality: Further research is very unlikely to change our confidence in the estimate of effect.

Moderate quality: Further research is likely to have an important impact on our confidence in the estimate of effect and may change the estimate.

Low quality: Further research is very likely to have an important impact on our confidence in the estimate of effect and is likely to change the estimate.

Very low quality: We are very uncertain about the estimate.

1 Various definitions of infection were used; we accepted the authors definition in each case.

2 In one trial (Psaila 1977) the follow-up period was not nominated.

3 Generation of random allocation sequence was unclear in two trials (Chiu 1993; Psaila 1977). Allocation concealment was unclear in four trials (Chiu 1993; Cordtz 1989; Jackson

1971; Psaila 1977). Outcome assessment was blinded in only one of the five studies (Ward 2001). However, although information about these quality issues were not available for some trials, results were similar across trials so we do not believe results were compromised by these omissions in reporting.

4 The total sample met requirements for optimal information size, and the total number of events exceeded 300. 
Summary of findings 2.

lodophore-impregnated adhesive drapes compared with no adhesive drapes for preventing surgical site infection

Patient or population: Patients undergoing surgery

Settings: Hospital

Intervention: lodophore-impregnated adhesive drapes

Comparison: No adhesive drapes

\begin{tabular}{|c|c|c|c|c|c|c|}
\hline \multirow[t]{3}{*}{ Outcomes } & \multicolumn{2}{|c|}{ Illustrative comparative risks ${ }^{\star}(95 \% \mathrm{Cl})$} & \multirow{2}{*}{$\begin{array}{l}\text { Relative effect } \\
(95 \% \mathrm{Cl})\end{array}$} & \multirow{2}{*}{$\begin{array}{l}\text { No. of Partici- } \\
\text { pants } \\
\text { (studies) }\end{array}$} & \multirow{2}{*}{$\begin{array}{l}\text { Quality of the } \\
\text { evidence } \\
\text { (GRADE) }\end{array}$} & \multirow[t]{2}{*}{ Comments } \\
\hline & Assumed risk & Corresponding risk & & & & \\
\hline & No adhesive drapes & $\begin{array}{l}\text { lodophore-impregnated adhe- } \\
\text { sive drapes }\end{array}$ & & & & \\
\hline \multirow{2}{*}{$\begin{array}{l}\text { Surgical site infection } \\
\text { Inspection of the wound } 1 \\
\text { (follow-up: } 3 \text { to } 6 \text { weeks) }\end{array}$} & \multicolumn{2}{|c|}{ Medium risk population } & \multirow{2}{*}{$\begin{array}{l}\text { RR } 1.03 \\
\text { (0.66 to } 1.6)\end{array}$} & \multirow{2}{*}{$\begin{array}{l}1113 \\
(2)\end{array}$} & \multirow{2}{*}{$\begin{array}{l}\oplus \oplus \oplus \ominus \\
\text { Moderate } 2,3\end{array}$} & \\
\hline & 45 per 1000 & $\begin{array}{l}46 \text { per } 1000 \\
(30 \text { to } 72)\end{array}$ & & & & \\
\hline
\end{tabular}

*The basis for the assumed risk (e.g. the median control group risk across studies) is provided in footnotes. The corresponding risk (and its $95 \% \mathrm{Cl}$ ) is based on the assumed risk in the comparison group and the relative effect of the intervention (and its $95 \% \mathrm{CI}$ ).

$\mathrm{Cl}$ : Confidence interval; RR: Risk ratio

GRADE Working Group grades of evidence

High quality: Further research is very unlikely to change our confidence in the estimate of effect.

Moderate quality: Further research is likely to have an important impact on our confidence in the estimate of effect and may change the estimate.

Low quality: Further research is very likely to have an important impact on our confidence in the estimate of effect and is likely to change the estimate.

Very low quality: We are very uncertain about the estimate.

1 A number of definitions of wound infection were used across the trials. We accepted the authors definition in all cases.

2 Although information about allocation concealment was unclear in one trial (Dewan 1987) and outcome assessment was not blinded in the Segal 2002 trial, we have judged

that this has not compromised the result.

3 There was imprecision on at least two counts; the total sample size was too small to meet optimal information size, and the total number of events was less than 300. 


\section{B A C K G R O U N D}

\section{Description of the condition}

Surgical site infection (SSI) is one of the most common postoperative complications, and has been estimated to occur in about $15 \%$ of cases of clean surgery and $30 \%$ of contaminated surgery cases (Bruce 2001). SSI is associated with longer recovery and further risks of additional complications, therefore increasing the risk of morbidity and mortality (Mangram 1999). However the incidence rate depends on a number of factors, including the definition of infection used, the intensity of surveillance, whether patients are followed up after discharge, and the prevalence of risk factors in the population studied (Smyth 2000). Risk factors associated with SSI have been grouped into two main categories: patient- or host-related and operationor procedure-related (Mangram 1999; Smyth 2000). Patient characteristics include age, obesity, co morbidities such as diabetes, remote infection, American Society of Anestheologists score (ASA) status, immunosuppressive therapy and length of preoperative hospital stay. Operative risk factors include length of surgery, skin preparation (including shaving and antiseptic skin preparation), type of procedure, antimicrobial prophylaxis and surgical technique (Mangram 1999; Smyth 2000).

Surgical wounds are frequently classified as either 'clean', 'clean contaminated', 'contaminated' or 'dirty-infected' with the latter categories associated with a higher infection rate (Lilani 2005). Many countries now benchmark their SSI rate using the National Nosocomial Infections Surveillance (NNIS) system risk index, in which wound classification is combined with the ASA status, length of surgery and whether surgery was undertaken laparoscopically to assess risk of SSI (Gaynes 2001). The additional per patient cost of SSI has been estimated to be between GBP 959 for abdominal hysterectomy to GBP 6103 for limb amputation (Coello 2005), and over USD 14,000 for an organ space SSI (Kashimura 2012). In the Unites States the estimated annual cost of SSIs is USD 3.5 billion to USD 10 billion (Thompson 2011).

\section{Description of the intervention}

The high additional costs associated with SSI have led to the adoption of strategies that could reduce the incidence of SSI. These strategies include administration of prophylactic antibiotics, use of antiseptic solutions for skin preparation, and the use of sterile disposable materials. One of the commonly used operative strategies to reduce SSI is the plastic adhesive drape (referred to hereafter as adhesive drape). This was first tested 50 years ago on a cohort of patients undergoing a range of abdominal surgeries (Payne 1956). The study had three main aims: 1) to test adherence of a polyvinyl drape to the skin; 2) to assess the level of wound contamination; and 3) to assess skin and wound reaction to the drape. Problems were found with adherence of the drape to the skin, despite trialing a number of skin preparation solutions. Positive cultures were recovered from two of the 51 wounds but no skin or wound reactions to the polyvinyl sheet were recorded. Since that time, use of adhesive drapes has become widespread and the product has undergone modifications to improve effectiveness (Ritter 1988; Yoshimura 2003). This review will focus on plastic (defined as polyethylene, polyurethane or polyvinyl) adhesive drapes (e.g. OpSite (Smith and Nephew), Ioban (3M Company, USA), Steridrape (3M United Kingdom) through which an incision is made.
Drapes may be either plain or impregnated with an antibacterial agent such as iodine.

\section{How the intervention might work}

For most SSIs, the source of the invading pathogen (or disease causing biological agent) is the patient's skin (Nichols 1996). Consequently, preoperative skin preparation is intended to render the skin as free as possible from bacteria that may enter the surgical wound. Although skin disinfection prior to surgery drastically reduces the number of bacteria on the skin's surface, recolonisation with bacteria from deeper skin layers and hair follicles may occur during the operation (Fleischmann 1996). Sterile surgical drapes, made of either linen or impervious paper, are used to prevent any contact with unprepared surfaces. Adhesive drapes are also used for this purpose and, are generally used in combination with other draping techniques, but they have an additional function; theoretically, they act as a microbial barrier, to prevent migration of contaminating bacteria from the skin to the operative site, for which there is some evidence (French 1976; Ha'eri 1983).

\section{Why it is important to do this review}

Although there is theoretical plausibility for the use of adhesive drapes, conflicting reports have been published regarding their usefulness in limiting bacteria around the surgical site (Katthagen 1992; Lilly 1970) and for preventing SSI (Ritter 1988; Swenson 2008). Recolonisation of the skin following antiseptic preparation is also more rapid under adhesive drapes compared with using no adhesive drapes in healthy volunteers (Falk-Brynhildsen 2013) and in cardiac surgery (Falk-Brynhildsen 2013a). Moreover, allergic reactions to povidone iodine are not unknown, and there is at least one case report of allergic contact dermatitis associated with the use of iodophor-impregnated incise drapes (Zokaie 2011). In a related systematic review, Edwards 2009 found no benefit in using iodophor-impregnated adhesive drapes to prevent postoperative surgical wound infection, when they were used as part of preoperative skin antisepsis. In light of these controversies, and because their use is widespread, a systematic review of the possible benefits and harms of adhesive drapes is justified to guide clinical practice.

\section{OB JECTIVES}

The primary objective of this systematic review was to assess the effect of plastic adhesive drapes used during surgery on surgical site infection (SSI) rates.

The secondary objectives were:

1. to determine the cost effectiveness of using plastic adhesive drapes;

2. to assess if there were any adverse effects associated with the use of plastic adhesive drapes; and

3. to determine whether different types of plastic adhesive drapes (polyethylene/polyurethane/polyvinyl) have differential effects on SSI rates. 


\section{METHODS}

\section{Criteria for considering studies for this review \\ Types of studies}

We included randomised controlled trials (RCTs) that evaluated the effectiveness of adhesive drapes (used alone or in combination with other drapes), in preventing SSI.

\section{Types of participants}

We considered for inclusion, trials recruiting people of any age or gender, undergoing any type of inpatient or outpatient surgery.

\section{Types of interventions}

The primary intervention was adhesive drapes (polyethylene, polyurethane or polyvinyl), through which an incision is made. Adhesive drapes may have been used alone or in combination with other drapes: woven (material) drapes or disposable (paper) drapes and with any antiseptic skin preparation. The comparison intervention was no adhesive drapes; other drapes such as woven (material) drapes or disposable (paper) drapes may have been used. We excluded trials evaluating plastic 'ring drapes' or 'V' drapes as the incision is not made through the drape.

Comparisons included:

- adhesive drapes (without added antimicrobial properties) compared with no adhesive drapes; and

- adhesive drapes (with added antimicrobial properties) compared with no adhesive drapes.

\section{Types of outcome measures}

\section{Primary outcomes}

Rates of surgical site infection (SSI). For the purposes of this review we accepted the definition of SSI used in the trial.

\section{Secondary outcomes}

- Mortality (any cause)

- Length of hospital stay

- Costs

- Hospital readmissions

- Adverse reactions (e.g. contact dermatitis, anaphylaxis)

- Other serious infection or infectious complication such as septicaemia or septic shock

\section{Search methods for identification of studies}

\section{Electronic searches}

For an outline of the search methods used in the third update of this review see Appendix 1.

For this fourth update we searched the following electronic databases.

- The Cochrane Wounds Group Specialised Register (searched 4th March 2015).

- The Cochrane Central Register of Controlled Trials (CENTRAL) (The Cochrane Library 2015, Issue 2).

- Ovid MEDLINE (2012 to 3rd March 2015).
- Ovid MEDLINE (In-Process \& Other Non-Indexed Citations, 2012 to 3rd March 2015)

- Ovid EMBASE (2012 to 3rd March 2015).

- EBSCO CINAHL (2012 to 4th March 2015).

We searched the Cochrane Central Register of Controlled Trials (CENTRAL) using the following strategy.

\#1 MeSH descriptor Surgical Wound Infection explode all trees \#2 MeSH descriptor Surgical Wound Dehiscence explode all trees \#3 MeSH descriptor Infection Control explode all trees

\#4 (surg* NEAR/5 infect*):ti,ab,kw \#5 (surg* NEAR/5 wound $\left.{ }^{\star}\right): \mathrm{ti}, \mathrm{ab}, \mathrm{kw}$ \#6 ( surg $^{\star}$ NEAR/5 site*):ti,ab,kw \#7 ( surg $^{\star}$ NEAR/5 incision*):ti,ab,kw \#8 ( surg $^{\star}$ NEAR/5 dehisc*):ti,ab,kw \#9 (wound ${ }^{*}$ NEAR/5 dehisc*):ti,ab,kw \#10 (wound NEAR/5 complication*):ti,ab,kw \#11 (\#1 OR \#2 OR \#3 OR \#4 OR \#5 OR \#6 OR \#7 OR \#8 OR \#9 OR \#10) \#12 (plastic NEAR/3 drape*):ti,ab,kw \#13 (adhes ${ }^{\star}$ NEAR/3 drape $\left.{ }^{\star}\right): t i, a b, k w$ \#14 (skin NEAR/3 drape*):ti,ab,kw \#15 (incis* NEAR/3 drape*):ti,ab,kw

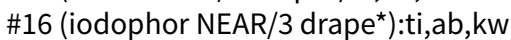
\#17 (iodine NEAR/3 drape*):ti,ab,kw \#18 (opsite or steridrape or ioban):ti,ab,kw \#19 (\#12 OR \#13 OR \#14 OR \#15 OR \#16 OR \#17 OR \#18) \#20 (\#11 AND \#19)

The search strategies for Ovid MEDLINE, Ovid EMBASE and EBSCO CINAHL can be found in Appendix 2, Appendix 3 and Appendix 4 respectively. We combined the Ovid MEDLINE search with the Cochrane Highly Sensitive Search Strategy for identifying randomised trials in MEDLINE: sensitivity- and precisionmaximising version (2008 revision); Ovid format (Lefebvre 2011). We combined the EMBASE search with the Ovid EMBASE filter developed by the UK Cochrane Centre, which is also cited in the Cochrane Handbook (Lefebvre 2011). We combined the CINAHL searches with the trial filters developed by the Scottish Intercollegiate Guidelines Network (SIGN) (SIGN 2012). We did not apply any date or language restrictions.

\section{Searching other resources}

We contacted researchers and manufactures in order to obtain any unpublished data. We also searched reference lists of potentially useful articles.

\section{Data collection and analysis}

\section{Selection of studies}

For the initial review, two authors (JW, AA) independently assessed the title and abstracts of references identified by the search strategy. We then retrieved full reports of all potentially relevant trials for further assessment of eligibility, based on the inclusion criteria. We settled differences of opinion by consensus or referral to the editorial base of the Wounds Group. There was no blinding of authorship. For this updated review, JW excluded trials and the Managing Editor of the Wounds Group verified their exclusion.

\section{Data extraction and management}

Two review authors (JW,AA) independently extracted the following data, using a piloted data extraction sheet: type of study, country, 
study setting, number of participants, sex, mean age, type of surgery, preoperative wound classification, predisposing risk factors by treatment groups, type of drape, draping procedure, type of preoperative skin preparation, prophylactic or therapeutic antibiotic use, all primary and secondary outcome measures reported and authors' conclusions. Clarification about aspects of the trial were required from all of the authors; five were untraceable (Chiu 1993; Cordtz 1989; Jackson 1971; Psaila 1977; Ward 2001). Additional trial details were received from Dewan 1987 and from the second author of the Segal 2002 trial. We also contacted manufacturers of plastic adhesive drapes (Johnson \& Johnson, 3M Company and Smith \& Nephew) to request details of any unpublished trials. A representative of each of these manufacturers responded; no current trials are underway and they were unaware of any unpublished trials.

\section{Assessment of risk of bias in included studies}

Two review authors independently assessed the quality of eligible trials, using a predefined quality assessment form, based on the assessment criteria outlined below. Disagreements between review authors were again resolved by consensus or referral to the editorial base of the Wounds Group. We contacted investigators of included trials to resolve any ambiguities. Each included study was assessed using the Cochrane Collaboration's tool for assessing risk of bias (Higgins 2011). This tool addresses six specific domains, namely sequence generation, allocation concealment, blinding, incomplete outcome data, selective outcome reporting, and other issues (e.g. extreme baseline imbalance) (see Appendix 5 for details of criteria on which the judgement was based). We assessed blinding and completeness of outcome data for each outcome separately. We completed a risk of bias table for each eligible study. We discussed any disagreement amongst authors to achieve a consensus.

We presented an assessment of risk of bias using a 'Risk of bias' summary figure, which presents all of the judgments in a cross-tabulation of study by entry. This display of internal validity indicates the weight the reader may give the results of each study.

We defined high quality trials as those receiving a 'low risk of bias' rating for the criterion of allocation concealment (central computerised randomisation service or sealed opaque envelopes), and for blinding of outcome assessment.

\section{Measures of treatment effect}

For dichotomous outcomes, we calculated risk ratio (RR) plus 95\% confidence intervals $(\mathrm{Cl})$. For continuous outcomes we calculated mean difference (MD) plus 95\% confidence intervals.

\section{Unit of analysis issues}

Individual patients were the analytic units in all trials, so there were no unit of analysis issues.

\section{Dealing with missing data}

If there was evidence of missing data, we contacted the study authors to request the information. Where trial authors could not provide missing data, we assessed the risk of bias of the missing data and decided if the missing data were of 'low' or 'high' risk of bias according to our risk of bias criteria (Higgins 2011). Or, if data were considered to be missing at random, we analysed the available information.

\section{Assessment of heterogeneity}

We assessed heterogeneity using the $\mathrm{Chi}^{2}$ statistic with significance being set at $P<0.10$. In addition, we investigated the degree of heterogeneity by calculating the $1^{2}$ statistic (Higgins 2002). If we identified evidence of significant heterogeneity (> 50\%), we explored potential sources of heterogeneity and a randomeffects approach to the analysis was undertaken. We conducted a narrative review of eligible studies where statistical synthesis of data from more than one study was not possible or considered not appropriate.

\section{Assessment of reporting biases}

We completed a 'Risk of bias' table for each eligible study and present an assessment of risk of bias using a 'Risk of bias' summary figure (Figure 1) which presents the judgements in a cross-tabulation. This display of internal validity indicates the weight the reader may give to the results of each study. 
Figure 1. Methodological quality graph: review authors' judgements about each methodological quality item presented as percentages across all included studies.

\section{Random sequence generation (selection bias)}

Allocation concealment (selection bias)

Blinding (performance bias and detection bias)

Incomplete outcome data (attrition bias)

Selective reporting (reporting bias)

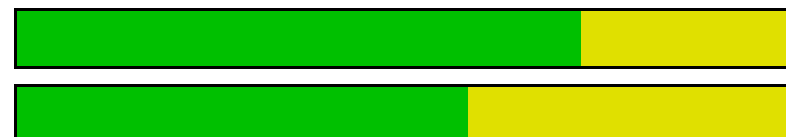

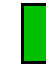

Other bias

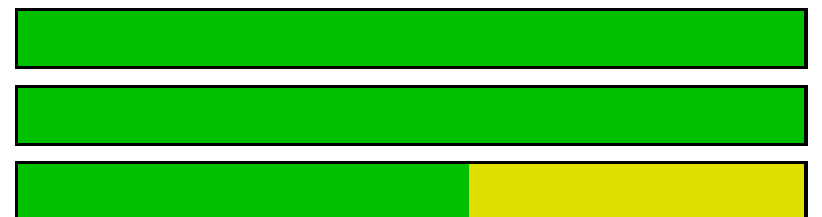

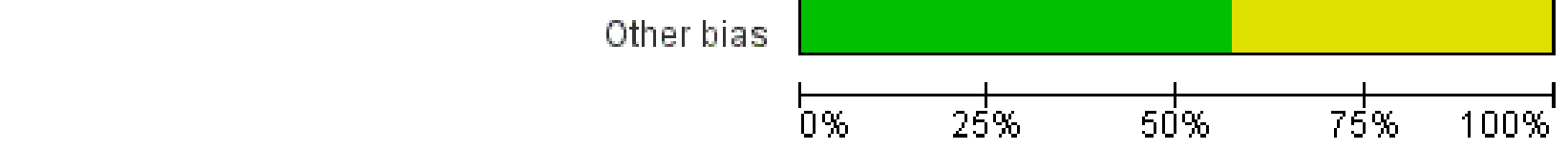

\section{Data synthesis}

We analysed data using Review manager software (RevMan 2011). One review author (JW) entered the data and the other author (AA) cross-checked the printout against their own data extraction forms. We calculated risk ratios (RRs) and 95\% confidence intervals (Cls) for dichotomous outcomes (risk ratio is the risk of infection in the intervention group divided by the risk of infection in the control group; a risk ratio of less than one indicates fewer infections in the intervention or adhesive drape group). We calculated mean differences (MDs) and 95\% Cls for continuous outcomes. Where appropriate, we pooled the results of comparable trials using a fixed-effect model, and we reported the pooled estimate together with its $95 \% \mathrm{Cl}$.

We included all eligible trials in the initial analysis and carried out preplanned sensitivity analyses to evaluate the effect of trial quality. This was done by excluding trials most susceptible to bias (based on the quality assessment): those with inadequate allocation concealment and uncertain or unblinded outcome assessment.

\section{Subgroup analysis and investigation of heterogeneity}

We had planned the following four subgroup analyses.

1. Clean surgery compared with contaminated surgery.

2. Individual compared with cluster allocation.

3. Prophylactic antibiotic compared with no prophylaxis.

4. Hair clipping compared with shaving.

The only subgroup analysis that was possible, based on available data, was of clean compared with contaminated surgery. Nor was it possible to undertake a planned sensitivity analysis based on the type of material the drape was made from due to insufficient detail about the products.

\section{RE S U L T S}

\section{Description of studies}

\section{Results of the search}

The initial search identified 84 possibly relevant titles, and after screening the titles we considered 18 as potentially useful. Both review authors independently retrieved abstracts or full-texts and reviewed them against the inclusion criteria. Eleven studies did not meet the inclusion criteria and we excluded them from the review. We excluded two further studies in subsequent updates (Breitner 1986; Swenson 2008). For this fourth update, we identified 49 new trials using the search strategy and follow-up of reference lists. Only one of these trials was potentially relevant but was later excluded (Falk-Brynhildsen 2013a), see Characteristics of excluded studies.

\section{Included studies}

From the initial search, seven RCTs (Chiu 1993; Cordtz 1989; Dewan 1987; Jackson 1971; Psaila 1977; Segal 2002; Ward 2001) met the inclusion criteria (see Characteristics of included studies). We included these seven trials of 4195 participants in the review, with individual trial sizes ranging between 141 to 1340 participants. Five of the trials compared an adhesive drape with no adhesive drape (Chiu 1993; Cordtz 1989; Jackson 1971; Psaila 1977; Ward 2001) and two compared an iodine-impregnated adhesive drape with no adhesive drape (Dewan 1987; Segal 2002). One study was a multicentre trial (Cordtz 1989); the remaining trials were single centre. An a priori sample size calculation, based on a $50 \%$ reduction in the infection rate, was reported in one study (Ward 2001). Segal 2002 reported a sample size calculation based on an analysis of results of a pilot study of 120 patients, the trial was then continued, recruiting a further 64 patients.

Surgical procedures included caesarean section (Cordtz 1989; Ward 2001), general or abdominal surgery (Dewan 1987; Jackson 1971; Psaila 1977), hip surgery (Chiu 1993) and cardiac surgery (Segal 2002). Surgical site infection (SSI) was not defined in one study (Chiu 1993); the Characteristics of included studies table contains details of other definitions used. 
Four trials used iodine and alcohol to prepare the operative site (Chiu 1993; Cordtz 1989; Dewan 1987; Jackson 1971); one used Savlon and alcoholic chlorhexidine (Psaila 1977); an iodophor/ alcohol water insoluble film was used in the Segal 2002 trial; and in the Ward 2001 trial, skin was swabbed with alcoholic chlorhexidine. In the Cordtz 1989 trial, participants were also randomised to have their wound re-disinfected prior to wound closure. Jackson 1971 ran a concurrent test of antibiotic spray in random cases.

Prophylactic cephalosporin was given to each patient at anaesthetic induction in the Chiu 1993 trial and all patients in the Ward 2001 trial received $1 \mathrm{~g}$ of cephazolin when the baby's cord was clamped, unless antibiotics were already being administered for therapy or prophylaxis. Antibiotic use was recorded by Cordtz 1989 and Segal 2002 but not reported by group. No information about antibiotic use was provided by other authors (Dewan 1987; Jackson 1971; Psaila 1977).

\section{Excluded studies}

The Characteristics of excluded studies table contains reasons for excluding 14 of these studies. In summary, six were not RCTs (Breitner 1986; Duvvi 2005; Fairclough 1986; Maxwell 1969; Swenson 2008; Yoshimura 2003), three did not report SSI rates (French 1976; Ha'eri 1983; Manncke 1984; Falk-Brynhildsen 2013a), one did not report the number of participants in each group (Lewis 1984) and an adhesive drape was not used in the remaining three trials (Nystrom 1980; Nystrom 1984; Williams 1972). We excluded one trial from the first review update which was waiting assessment, as it reported colonisation rates but not SSI rates (Breitner 1986).

\section{Risk of bias in included studies}

(See risk of bias Figure 1; Figure 2 and Appendix 5) 
Figure 2. Methodological quality summary: review authors' judgements about each methodological quality item for each included study.

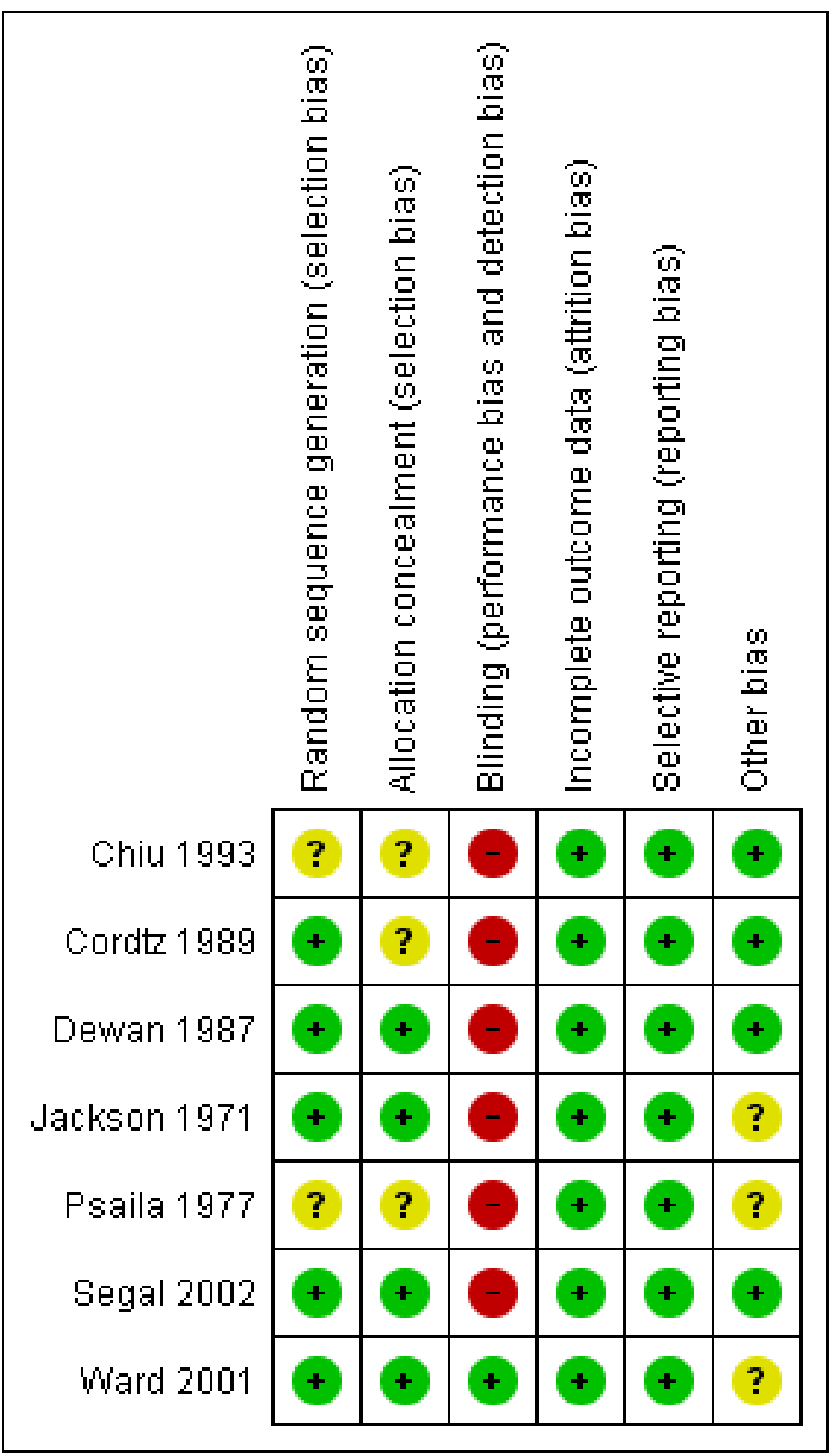

\section{Random sequence generation}

In all trials, the trial authors stated that participants were randomly allocated to the intervention. It was unclear how the allocation sequence was generated in three trials (Chiu 1993; Psaila 1977; Segal 2002). In the Cordtz 1989 trial, the National Centre for Hospital Hygiene was responsible for the randomisation process; Dewan 1987 and Ward 2001 used a random number table and in the Jackson 1971 trial, a 'spin of the coin' was used.

\section{Allocation concealment}

Allocation concealment was adequate in three studies. Segal 2002 asked surgeons participating in the trial to draw the treatment allocation from a 'closed sack' at the beginning of surgery and Ward 2001 and Dewan 1987 used sealed envelopes for group allocation. In other studies the information was not available to judge (unclear), although we contacted trial authors where possible (Chiu 1993; Cordtz 1989; Jackson 1971; Psaila 1977). 


\section{Blinding}

It was impossible for surgeons to be blinded to the intervention. In the Ward 2001 and Dewan 1987 trials, outcomes were assessed by staff who were unaware of group assignment. The study investigators inspected wounds for signs of infection in the Jackson 1971 and Segal 2002 trials. In all other trials it was unclear who was responsible for assessing outcomes, and whether those who did inspect wounds for signs of infection were aware of group assignment (Chiu 1993; Cordtz 1989; Psaila 1977).

\section{Incomplete outcome data}

One trial did not indicate the period of follow-up (Psaila 1977). In the remaining trials, follow-up ranged between five days and six months (Characteristics of included studies table). In the Dewan 1987 trial, 46 patients (4.2\%) were unable to be tracked and were excluded from the analysis. Based on reported data, follow-up appeared to be complete in all of the other included trials. However, the absence of detailed participant flow charts, or any reference to the number who started the trial and were unable to be followed up, makes assessment of rates difficult, particularly as the followup periods were lengthy in some studies, increasing the likelihood of incomplete follow-up.

\section{Selective reporting}

Results for all expected outcomes were reported in all of the trials.

\section{Other bias}

\section{Intention-to-treat analysis}

None of the trials reported group assignment violations, and so it is difficult to assess whether patient outcomes were analysed in the group to which they were assigned. None of the trials specifically reported that they used an intention-to-treat analysis.

\section{Baseline comparability}

No information was available about baseline comparability for five trials (Chiu 1993; Cordtz 1989; Jackson 1971; Psaila 1977; Segal 2002). In the Dewan 1987 trial, the author stated that groups were similar for all risk factors but no data was presented. Ward 2001 stated that, apart from age and parity, groups were comparable at baseline but again, no data were available for comparison.

\section{Conflict of interest}

No conflict of interests issues were reported by any of the trial authors

\section{Effects of interventions}

See: Summary of findings for the main comparison; Summary of findings 2

This review includes seven studies involving 4195 participants of whom 2133 were in the treatment group and 2062 formed the control group. All seven trials recorded incidence of surgical site infection (SSI) as an outcome. Surgical procedures included general or abdominal surgery (Dewan 1987; Jackson 1971; Psaila 1977), caesarean section (Cordtz 1989; Ward 2001), cardiac surgery (Segal 2002) and hip surgery (Chiu 1993). Based on our quality criteria, we considered the trials of Dewan 1987 and Ward 2001 to have a low risk of bias. The remaining five trials (Chiu 1993; Cordtz 1989;
Jackson 1971; Psaila 1977; Segal 2002) contained a moderate risk of bias. However, as results from all trials were not dissimilar, we combined all of the eligible trials in the meta-analyses.

We undertook two comparisons: adhesive drapes compared with no adhesive drapes (Data and analyses Table 1) (Chiu 1993; Cordtz 1989; Jackson 1971; Psaila 1977; Ward 2001) and iodineimpregnated adhesive drapes compared with no adhesive drapes (Analysis 2.1) (Dewan 1987; Segal 2002).

\section{Adhesive drapes compared with no adhesive drapes (Analysis:} 1)

\section{Primary outcome}

\section{Surgical site infection (SSI)}

Five studies were included in this comparison (Cordtz 1989; Chiu 1993; Jackson 1971; Psaila 1977; Ward 2001). These studies included 3082 participants, of whom 1556 were in the adhesive drape group and 1526 were in the no adhesive drape group. Although the studies covered a 30-year time span and included a range of different types of surgery, we did not detect any heterogeneity $\left(I^{2}=0 \%\right)$. Pooling these studies (fixed-effect model) indicated significantly more SSIs in the adhesive drape group, (RR $1.23,95 \% \mathrm{Cl} 1.02$ to $1.48, \mathrm{P}=0.03$, Analysis 1.1 ). The overall event rate was $13.7 \%$ and $11.2 \%$ in the adhesive drape group and no drape group, respectively.

\section{Surgical site infection - by preoperative wound classification}

A single trial of 921 participants analysed infection rates based on preoperative infection risk classifications (Jackson 1971). In this trial there was no significant effect of using an adhesive drape overall, although infection rates were lower for the no adhesive drape group. Results did not vary depending on baseline risk of infection: RR (overall) $1.20,95 \% \mathrm{Cl} 0.86$ to 1.66 ; RR (for clean wounds) $1.37,95 \% \mathrm{Cl} 0.53$ to 3.53 ; RR (for potentially infected wounds) $1.24,95 \% \mathrm{Cl} 0.80$ to 1.92 ; and RR (for infected wounds) $1.03,95 \% \mathrm{Cl} 0.60$ to 1.75 (Analysis 1.2). We have reported results from this trial as they were presented in the published paper, even though there was a minor discrepancy between results in the text and those in the tables. For example, in the text, 52 of the 448 cases in the no adhesive drape group became infected. In the table, when cases were classified as clean, potentially infected and infected, totals were 51 infections among 445 cases. Similarly in the adhesive drape group, 67 infections were reported in 473 patients in the text and 67 of 476 in the tables. Attempts to contact investigators were unsuccessful, however, using either set of results did not affect the overall level of significance for this outcome.

\section{Secondary outcome}

\section{Length of stay}

Ward 2001 was the only trial to report length of stay. The analysis was divided into two subgroups: length of stay for those with a SSI $(n=64)$ and those without a SSI $(n=539)$. In the infected subgroup, the mean length of stay in the adhesive drape group was 10.4 days (standard deviation (SD) 3.9 days), this was not statistically different from the mean length of stay in the no adhesive drape group (10.2 days, SD 3.9 days). Length of stay was much shorter among those without a SSI. In the adhesive drape group it was 5.2 days (SD 1.3 days) and also 5.2 days (SD 1.3 days) in the no adhesive drape group. We did not find any statistical difference in length of stay 
between the adhesive drape and no adhesive drape groups in either of these subgroups (Analysis 1.3).

None of the trials provided information about any of the other predefined secondary outcomes (mortality, cost, hospital readmissions, adverse reactions e.g. contact dermatitis, anaphylaxis), or other serious infection or infectious complication, such as septicaemia or septic shock.

\section{lodine-impregnated adhesive drapes compared with no adhesive drapes (Analysis:2)}

\section{Primary outcome}

\section{Surgical site infection (SSI)}

Two studies compared iodine-impregnated adhesive drapes with no adhesive drapes (Dewan 1987; Segal 2002). These studies included 1113 participants, of whom 577 were in the iodineimpregnated adhesive drape group and 536 were in the no adhesive drape group. In the absence of heterogeneity $\left(I^{2}=0 \%\right)$ we pooled the studies. There was no significant difference in SSI rates between the two groups ( $R R 1.03,95 \% \mathrm{Cl} 0.66$ to $1.60, \mathrm{P}=0.89$ Analysis 2.1 ).

\section{DISCUSSION}

The conclusions from the original version of this review remain unchanged in this update. Although adhesive drapes are widely used in surgery to prevent surgical site infections (SSIs), the most recent recommendations for control of SSIs remains equivocal regarding the use of adhesive drapes for this purpose (Alexander 2011). Consequently, the primary focus of this review was to address the effectiveness of adhesive drapes in preventing SSI. We identified seven studies, including 4195 patients. The main finding of this review is that adhesive drapes are not associated with a reduced infection rate compared with no adhesive drapes, and appear to be associated with an increased risk of infection. The most obvious explanation for this result is that, if adequately disinfected prior to surgery, the patient's skin is unlikely to be a primary cause of SSI; so attempts to isolate the skin from the wound, using an adhesive drape, may be pointless and potentially harmful as excessive moisture under plastic drapes may encourage bacteria residing in hair follicles to migrate to the surface and multiply (Chiu 1993).

In the only trial to report on length of stay, the use of adhesive drapes did not appear to affect the duration of hospitalisation. There was no available evidence for our other preplanned outcomes of interest; mortality, cost, hospital readmissions or adverse reactions.

Three of the trials included in the review had concurrent interventions. Segal 2002 had four arms to the study, two of which did not involve a comparison between draping methods. In the analysis, we included the two arms of the study that included a draping comparison only. We believe it is unlikely that this design would have had an impact on the outcome as patients were mutually exclusive. Similarly, in the Psaila 1977 trial, ring drapes were used in a third group. Cordtz 1989 allocated patients to four groups, adhesive drape or no adhesive drape combined with re-disinfection or no re-disinfection. Although there was a lower rate of SSI in the re-disinfection group, the reduction was similar irrespective of the type of drape used.

Studies were of variable quality with only two trials (Dewan 1987; Ward 2001) meeting our criteria for high quality (receiving an A rating for the criterion of allocation concealment and for blinding of outcome assessment). The reporting aspects of other trials were poor, making it difficult to assess study quality. However, results of all but one of the trials were in a similar direction, favouring no adhesive drapes, providing some confidence in results. Although verification remains a problem, with many older studies, where contact with authors is impossible. Only the Psaila 1977 trial had a non-significant trend favouring adhesive drapes. This was a small study of 116 participants. The authors randomly allocated patients to two groups (adhesive drape and ring drape) and then stated, "in a control group, linen towels alone were used". We included outcomes from the control group in this study as the 'no adhesive drape' group in our analysis, but it was unclear how this group was selected. We are uncertain if any publication bias affected results; we did not find any unpublished studies.

Finally, it is unclear if all of the products used in the trials were similar. Trade names of adhesive drapes have changed over the 30-year time span this review covers. Whether this has led to a qualitative improvement in the product is unclear. No specific details were provided about, for example, the density of the material or its adherability. Irrespective of this, results have remained consistent over time suggesting that any improvements or changes to the product have not affected SSI rates.

\section{AUTHORS' CONCLUSIONS}

\section{Implications for practice}

Evidence from this review suggests that use of intraoperative, incisional adhesive drapes is unlikely to reduce SSI rates, and may increase them.

\section{Implications for research}

A large, high quality definite RCT may be warranted to determine whether modern adhesive drapes do prevent or reduce SSI rates.

\section{ACKNOWLEDGEMENTS}

The authors would like to acknowledge the contribution of the Wounds Group Editors: Nicky Cullum, Andrea Nelson and David Margolis; the Trials Search Co-ordinator Ruth Foxlee for assistance with the search strategy; Gill Worthy the Statistical Editor; referees Allyson Lipp, Jac Dines and Durhane Wong-Rieger; and the copy editors, Elizabeth Royle and Clare Dooley for their valuable suggestions. Thanks also to Sally Bell-Syer for her advice, for being always available and keeping the process moving so efficiently. 


\section{R E F E R E N C E S}

\section{References to studies included in this review}

Chiu 1993 \{published data only\}

Chiu KY, Lau SK, Fung B, Ng KH, Chow SP. Plastic adhesive drapes and wound infection after hip fracture surgery. Australian and New Zealand Journal of Surgery 1993;63:798-801.

\section{Cordtz 1989 \{published data only\}}

Cordtz T, Schouenborg L, Laursen K, Daugaard HO, Buur K, Munk Christensen $B$, et al. The effect of incisional plastic drapes and redisinfection of operation site on wound infection following caesarean section. Journal of Hospital infection 1989;13(3):267-72.

\section{Dewan 1987 \{published data only\}}

Dewan PA, Van Rij AM, Robinson RG, Skeggs GB, Fergus M. The use of an iodophor-impregnated plastic incise drape in abdominal surgery - a controlled clinical trial. Australian and New Zealand Journal of Surgery 1987;57(11):859-63.

\section{Jackson 1971 \{published data only\}}

Jackson DW, Pollock AV, Tindal DS. The value of a plastic adhesive drape in the prevention of wound infection. A controlled trial. British Journal of Surgery 1971;58(5):340-2.

\section{Psaila 1977 \{published data only\}}

Psaila JV, Wheeler MH, Crosby DL. The role of plastic wound drapes in the prevention of wound infection following abdominal surgery. British Journal of Surgery 1977;64(10):729-32.

\section{Segal 2002 \{published data only\}}

Segal CG, Anderson JJ. Preoperative skin preparation of cardiac patients. AORN Journal 2002;76(5):821-8.

\section{Ward 2001 \{published data only\}}

Ward HR, Jennings OG, Potgieter P, Lombard CJ, Ward HR, Jennings OG, et al. Do plastic adhesive drapes prevent post caesarean wound infection?. Journal of Hospital Infection 2001;47(3):230-4.

\section{References to studies excluded from this review}

\section{Breitner 1986 \{published data only\}}

Breitner S, Ruckdeschel G. Bacteriologic studies of the use of incision drapes in orthopedic operations. Unfallchirurgie 1986;12(6):301-4.

\section{Duvvi 2005 \{published data only\}}

Duvvi SK, Lo S, Spraggs PD. A plastic drape in nasal surgery. Plastic and Reconstive Surgery 2005;116(7):2041-2.

\section{Fairclough 1986 \{published data only\}}

Fairclough JA, Johnson D, Mackie I. The prevention of wound contamination by skin organisms by the pre-operative application of an iodophor impregnated plastic adhesive drape. Journal of International Medical Research 1986;14(2):105-9.
Falk-Brynhildsen 2013a \{published data only\}

Falk-Brynhildsen K, Friberg O, Söderquist B, Nilsson UG. Bacterial recolonization of the skin and wound contamination during cardiac surgery: a randomized controlled trial of the use of plastic adhesive drapes compared with bare skin. Journal of Hospital Infection 2013;84:151-158.

French 1976 \{published data only\}

French ML, Eitzen HE, Ritter MA. The plastic surgical adhesive drape: an evaluation of its efficacy as a microbial barrier. Annals of Surgery 1976;184(1):46-50.

Ha'eri 1983 \{published data only\}

Ha'eri GB. The efficacy of adhesive plastic incise drapes in preventing wound contamination. International Surgery 1983;68(1):31-2.

Lewis 1984 \{published data only\}

Lewis DA, Leaper DJ, Speller DC. Prevention of bacterial colonization of wounds at operation: comparison of iodineimpregnated ('Ioban') drapes with conventional methods. Journal of Hospital Infection 1984;5(4):431-7.

\section{Manncke 1984 \{published data only\}}

Manncke M, Heeg P. Experimental and clinical studies of the efficacy of an antimicrobial incision drape. Der Chirurg; Zeitschrift für alle Gebiete der operativen Medizen 1984;55(8):515-8.

Maxwell 1969 \{published data only\}

Maxwell JG, Ford CR, Peterson DE, Richards RC. Abdominal wound infections and plastic drape protectors. American Journal of Surgery 1969;116(6):844-8.

\section{Nystrom 1980 \{published data only\}}

Nystrom PO, Brote L. Effects of a plastic wound drape on contamination with enterobacteria and on infection after appendicectomy. Acta Chirurgica Scandinavica 1980;146(1):67-70.

\section{Nystrom 1984 \{published data only\}}

Nystrom PO, Broome A, Hojer H, Ling L. A controlled trial of a plastic wound ring drape to prevent contamination and infection in colorectal surgery. Diseases of the Colon and Rectum 1984;27:451-3.

\section{Swenson 2008 \{published data only\}}

Swenson BR, Camp TR, Mulloy DP, Sawyer RG. Antimicrobialimpregnated surgical incise drapes in the prevention of mesh infection after ventral hernia repair. Surgical infections 2008;9(1):23-32.

\section{Williams 1972 \{published data only\}}

Williams JA, Oates GD, Brown PP, Burden DW, McCall J, Hutchison AG, et al. Abdominal wound infections and plastic wound guards. British Journal of Surgery 1972;59(2):142-6. 
Yoshimura 2003 \{published data only\}

Yoshimura Y, Kubo S, Hirohashi K, Ogawa M, Morimoto K, Shirata K, et al. Plastic iodophor drape during liver surgery operative use of the iodophor-impregnated adhesive drape to prevent wound infection during high risk surgery. World Journal of Surgery 2003;27(6):685-8.

\section{Additional references}

\section{Alexander 2011}

Alexander JW, Solomkin JS, Edwards MJ. Updated recommendations for control of surgical site infections. Annals of Surgery 2011;253:1083-93.

\section{Bruce 2001}

Bruce J, Russell EM, Mollinson J, Krukowski ZH. The measurement and monitoring of surgical adverse events. Health Technology Assessment 2001;5:1-194.

\section{Coello 2005}

Coello R, Charlett A, Wilson J, Ward V, Pearson A, Borriello P. Adverse impact of surgical site infections in English hospitals. Journal of Hospital Infection 2005;60:93-103.

\section{Edwards 2009}

Edwards PS, Lipp A, Holmes A. Preoperative skin antiseptics for preventing surgical wound infections after clean surgery. Cochrane Database of Systematic Reviews 2009, Issue 3. [DOI: 10.1002/14651858.CD003949.pub2]

\section{Falk-Brynhildsen 2013}

Falk-Brynhildsen K, Friberg O, Söderquist B, Nilsson UG. Bacterial colonization of the skin following aseptic preoperative preparation and impact of the use of plastic adhesive drapes. Biological Research for Nursing 2013; Vol. 15:242-248. [DOI: 10.1177/1099800411430381]

\section{Fleischmann 1996}

Fleischmann W, Meyer H, von Baer A. Bacterial recolonization of the skin under a polyurethane drape in hip surgery. Journal of Hospital Infection 1996;34(2):107-16.

\section{Gaynes 2001}

Gaynes RP, Culver DH, Horan TC, Edwards JR, Richards C, Tolson JS. Surgical site infection (SSI) rates in the United States, 1992-1998: the National Nosocomial Infections Surveillance System basic SSI risk index. Clinical Infectious Diseases 2001;33(Suppl 2):S69-77.

\section{Higgins 2002}

Higgins JPT, Thompson SG. Quantifying heterogeneity in a meta-analysis. Statistics in Medicine 2002;21:539-58.

\section{Higgins 2011}

Higgins JPT, Altman DG, Sterne JAC (editors). Chapter 8. Assessing risk of bias in included studies. In: Higgins JPT, Green S (editors). Cochrane Handbook for Systematic Reviews of Interventions Version 5.1.0 [updated March 2011]. The Cochrane Collaboration, 2011. Available from www.cochranehandbook.org.

\section{Kashimura 2012}

Kashimura N, Kusachi S, Konishi T, Shimizu J, Kusunoki M, Oka M, et al. Impact of surgical site infection after colorectal surgery on hospital stay and medical expenditure in Japan. Surgery Today 2012 Jan 31 [Epub ahead of print].

\section{Katthagen 1992}

Katthagen BD, Zamani P, Jung W. Effect of surgical draping on bacterial contamination in the surgical field. Zeitschrift für Orthopädie und ihre Grenzgebiete 1992;130:230-5.

\section{Lefebvre 2011}

Lefebvre C, Manheimer E, Glanville J. Chapter 6: Searching for studies. In: Higgins JPT, Green S (editors). Cochrane Handbook for Systematic Reviews of Interventions Version 5.1.0 [updated March 2011]. The Cochrane Collaboration, 2011. Available from www.cochrane-handbook.org.

\section{Lilani 2005}

Lilani SP, Jangale N, Chowdhary A, Daver GB. Surgical site infection in clean and clean-contaminated cases. Indian Journal of Medical Microbiology 2005;23:249-52.

\section{Lilly 1970}

Lilly HA, Lowbury EJ, London PS, Porter MF. Effects of adhesive drapes on contamination of operation wounds. Lancet 1970;7670:431-2.

\section{Mangram 1999}

Mangram AJ, Horan TC, Pearson ML, Silver LC, Jarvis WR. Guidelines for prevention of surgical site infection, 1999. Hospital Infection Control Practices Advisory Committee. Infection Control and Hospital Epidemiology 1999;20:250-78.

\section{Nichols 1996}

Nichols RN. Surgical infections: prevention and treatment -1965 to 1995. American Journal of Surgery 1996;172(1):68-74.

\section{Payne 1956}

Payne JT. An adhesive surgical drape. American Journal of Surgery 1956;91:110-12.

\section{RevMan 2011 [Computer program]}

The Nordic Cochrane Centre, The Cochrane Collaboration. Review Manager (RevMan). Version 5.1. Copenhagen: The Nordic Cochrane Centre, The Cochrane Collaboration, 2011.

\section{Ritter 1988}

Ritter MA, Campbell ED. Retrospective evaluation of an iodophor-incorporated antimicrobial plastic adhesive wound drape. Clinical Orthopaedics and Related Research 1988;228:307-8.

\section{SIGN 2012}

Scottish Intercollegiate Guidelines Network (SIGN). Search filters. www.sign.ac.uk/methodology/filters.html\#random (Accessed 10 August 2012).

\section{Smyth 2000}

Smyth ET, Emmerson AM. Surgical site infection surveillance. Journal of Hospital Infection 2000;45:173-84. 


\section{Thompson 2011}

Thompson KM, Oldenburg WA, Deschamps C, Rupp WC, Smith CD. Chasing zero: the drive to eliminate surgical site infections. Annals of Surgery 2011;254(3):430-6.

\section{CHARACTERISTICS OF STUDIES}

Characteristics of included studies [ordered by study ID]

\section{Chiu 1993}

$\begin{array}{ll}\text { Methods } & \text { Study type: single-centre RCT } \\ & \text { Follow-up period: } 6 \text { months }\end{array}$

\begin{tabular}{ll}
\hline Participants & People undergoing acute hip fracture surgery \\
\hline Interventions & Opsite (Smith \& Nephew) adhesive plastic incisional drapes compared with no incisional drapes \\
\hline Outcomes & $\begin{array}{l}\text { Surgical wound infection (reported as deep and superficial infection). No definition of infection provid- } \\
\text { ed } \\
\text { Bacterial colonisation }\end{array}$ \\
\hline
\end{tabular}

Notes

\section{Risk of bias}

\begin{tabular}{lll}
\hline Bias & Authors' judgement & Support for judgement \\
\hline $\begin{array}{l}\text { Random sequence genera- } \\
\text { tion (selection bias) }\end{array}$ & Unclear risk & Method not described \\
\hline $\begin{array}{l}\text { Allocation concealment } \\
\text { (selection bias) }\end{array}$ & Unclear risk & Method not described \\
\hline $\begin{array}{l}\text { Blinding (performance } \\
\text { bias and detection bias) } \\
\text { All outcomes }\end{array}$ & High risk & $\begin{array}{l}\text { Masking was impossible for surgeons } \\
\text { It is unclear if patients were aware of their group allocation } \\
\text { Whether outcome assessors were masked is unclear. The author states "After } \\
\text { the operation, the wound was observed for clinical infection" but there was } \\
\text { no indication of who undertook this assessment nor if those assessing the out- } \\
\text { come were aware of the group allocation }\end{array}$
\end{tabular}

$\begin{array}{ll}\begin{array}{l}\text { Incomplete outcome data } \\ \text { (attrition bias) }\end{array} & \begin{array}{l}\text { The authors state that } 120 \text { patients were enrolled and results were available } \\ \text { for all of these patients. No mention of intention-to-treat analysis was made }\end{array}\end{array}$

All outcomes

\begin{tabular}{lll}
\hline $\begin{array}{l}\text { Selective reporting (re- } \\
\text { porting bias) }\end{array}$ & Low risk & Results for all expected outcomes were reported \\
\hline Other bias & Low risk & $\begin{array}{l}\text { No competing interests were declared. Although no data were shown, the au- } \\
\text { thors stated that patients were matched for relevant risk factors at baseline }\end{array}$ \\
\hline
\end{tabular}

Cordtz 1989

$\begin{array}{ll}\text { Methods } & \text { Study type: multi-centre RCT } \\ & \text { Follow-up period: } 14 \text { days }\end{array}$


Cordtz 1989 (Continued)

\begin{tabular}{ll} 
Participants & Women undergoing caesarean section. Includes infected and possibly infected cases \\
\hline Interventions & Adhesive plastic incisional drapes compared with no adhesive plastic incisional drapes \\
\hline Outcomes & $\begin{array}{l}\text { Surgical wound infection (defined as possibly infected if there was localised erythema and/or serous } \\
\text { secretion without the presence of pus) }\end{array}$
\end{tabular}

Notes

\section{Risk of bias}

\begin{tabular}{lll}
\hline Bias & Authors' judgement & Support for judgement \\
\hline $\begin{array}{l}\text { Random sequence genera- } \\
\text { tion (selection bias) }\end{array}$ & Low risk & Random allocation, using block design, in blocks of eight \\
\hline $\begin{array}{l}\text { Allocation concealment } \\
\text { (selection bias) }\end{array}$ & Unclear risk & $\begin{array}{l}\text { Not described. However, the study, which included eight hospitals, was carried } \\
\text { out under the supervision of the Danish National Centre for Hospital Hygiene, } \\
\text { so it is likely that an appropriate method of allocation concealment was used }\end{array}$ \\
\hline $\begin{array}{l}\text { Blinding (performance } \\
\text { bias and detection bias) } \\
\text { All outcomes }\end{array}$ & High risk & $\begin{array}{l}\text { Masking was impossible for surgeons } \\
\text { It is unclear if patients were aware of their group allocation } \\
\text { Whether outcome assessors were masked is unclear. The author states "Post- } \\
\text { operative observations of the wounds were continued in hospital until the } \\
\text { fourteenth post-operative day" but there was no indication of who undertook } \\
\text { this assessment nor if the assessors were aware of the group allocation }\end{array}$
\end{tabular}

Incomplete outcome data Low risk (attrition bias)

All outcomes
64 patients were excluded before randomisation but details by group were not provided. No mention of intention-to-treat analysis was made

\begin{tabular}{lll}
\hline $\begin{array}{l}\text { Selective reporting (re- } \\
\text { porting bias) }\end{array}$ & Low risk & Results for all expected outcomes were reported \\
\hline Other bias & Low risk & No competing interests declared. No baseline data reported \\
\hline
\end{tabular}

Dewan 1987

\begin{tabular}{ll}
\hline Methods & $\begin{array}{l}\text { Study type: single-centre RCT } \\
\text { Follow-up period: } 3 \text { weeks }\end{array}$ \\
\hline Participants & People undergoing general surgery \\
\hline Interventions & $\begin{array}{l}\text { loban (3M Company) iodine-impregnated adhesive plastic incisional drapes compared with no incision- } \\
\text { al drapes }\end{array}$ \\
\hline Outcomes & $\begin{array}{l}\text { Surgical wound infection (defined as a wound that discharged pus or if the fluid discharging from the } \\
\text { wound was associated with a positive bacterial culture or if erythema was present man } 1 \mathrm{~cm} \text { lat- } \\
\text { eral to the wound) } \\
\text { Death } \\
\text { Bacterial colonisation }\end{array}$ \\
\hline
\end{tabular}

\section{Notes}

\section{Risk of bias}


Dewan 1987 (Continued)

\begin{tabular}{lll} 
Bias & Authors' judgement & Support for judgement \\
\hline $\begin{array}{l}\text { Random sequence genera- } \\
\text { tion (selection bias) }\end{array}$ & Low risk & Random number table \\
\hline $\begin{array}{l}\text { Allocation concealment } \\
\text { (selection bias) }\end{array}$ & Low risk & $\begin{array}{l}\text { Surgeons sequentially selected the allocation from the random numbers table } \\
\text { located in the operating room Consequently, surgeons would have been aware } \\
\text { of the next allocation }\end{array}$
\end{tabular}

Blinding (performance $\quad$ High risk
bias and detection bias)

Masking was impossible for surgeons

All outcomes

It is unclear if patients were aware of their group allocation

Outcome assessment was masked "Postoperatively, wound follow-up was carried out by the infection control nurse who was unaware whether the drape had been used or not"

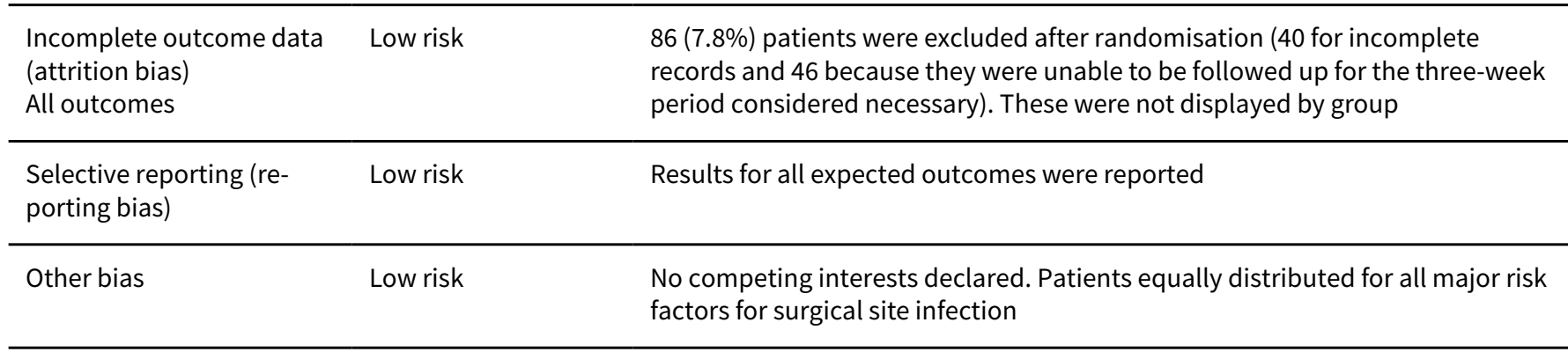

\section{Jackson 1971}

\begin{tabular}{ll}
\hline Methods & $\begin{array}{l}\text { Study type: single-centre RCT } \\
\text { Follow-up period: } 1 \text { month }\end{array}$ \\
\hline Participants & People undergoing general surgery \\
\hline Interventions & Adhesive plastic incisional drapes (Band-aid) compared with no adhesive plastic incisional drapes \\
\hline Outcomes & Surgical wound infection (defined as a wound discharging pus included stitch abscess) \\
\hline Notes &
\end{tabular}

\section{Risk of bias}

\begin{tabular}{|c|c|c|}
\hline Bias & Authors' judgement & Support for judgement \\
\hline $\begin{array}{l}\text { Random sequence genera- } \\
\text { tion (selection bias) }\end{array}$ & Low risk & Spin of a coin \\
\hline $\begin{array}{l}\text { Allocation concealment } \\
\text { (selection bias) }\end{array}$ & Low risk & $\begin{array}{l}\text { The coin was 'spun' at the beginning of the operation. Allocation would have } \\
\text { been concealed until then and the next allocation would be unpredictable }\end{array}$ \\
\hline $\begin{array}{l}\text { Blinding (performance } \\
\text { bias and detection bias) } \\
\text { All outcomes }\end{array}$ & High risk & $\begin{array}{l}\text { Masking was impossible for surgeons } \\
\text { It is unclear if patients were aware of their group allocation } \\
\text { Two of the authors, who were also surgeons involved in the trial, followed up } \\
\text { all patients until one month after the surgery to record any wound infection }\end{array}$ \\
\hline $\begin{array}{l}\text { Incomplete outcome data } \\
\text { (attrition bias) }\end{array}$ & Low risk & Follow-up data was reported on all enrolled participants \\
\hline
\end{tabular}


Jackson 1971 (Continued)

All outcomes

Selective reporting (re- Low risk $\quad$ Results for all expected outcomes were reported
porting bias)

\begin{tabular}{|c|c|c|}
\hline Other bias & Unclear risk & $\begin{array}{l}\text { The investigators "concurrently ran a test of an antibiotic spray in random cas- } \\
\text { es." Results were to be reported separately. It is unclear if the spray was used } \\
\text { equally between groups } \\
\text { No baseline data were reported. No competing interests reported }\end{array}$ \\
\hline
\end{tabular}

\section{Psaila 1977}

\begin{tabular}{ll}
\hline Methods & $\begin{array}{l}\text { Study type: Single-centre RCT } \\
\text { Follow-up period: Not defined }\end{array}$ \\
\hline Participants & People undergoing abdominal surgery \\
\hline Interventions & $\begin{array}{l}\text { Adhesive plastic incisional drapes compared with no adhesive plastic incisional drapes and a ring } \\
\text { drape }\end{array}$ \\
\hline Outcomes & $\begin{array}{l}\text { Surgical wound infection (defined as erythema around sutures or wound edge with an accompanying } \\
\text { pyrexia; } \\
\text { discharge or exudate from the wound; wound breakdown) } \\
\text { Bacterial colonisation }\end{array}$ \\
\hline
\end{tabular}

\section{Notes}

\section{Risk of bias}

\begin{tabular}{|c|c|c|}
\hline Bias & Authors' judgement & Support for judgement \\
\hline $\begin{array}{l}\text { Random sequence genera- } \\
\text { tion (selection bias) }\end{array}$ & Unclear risk & Method not described \\
\hline $\begin{array}{l}\text { Allocation concealment } \\
\text { (selection bias) }\end{array}$ & Unclear risk & Method not described \\
\hline $\begin{array}{l}\text { Blinding (performance } \\
\text { bias and detection bias) } \\
\text { All outcomes }\end{array}$ & High risk & $\begin{array}{l}\text { Masking was impossible for surgeons } \\
\text { It is unclear if patients were aware of their group allocation } \\
\text { Wounds were inspected daily after the third day to identify evidence of infec- } \\
\text { tion but it is not clear who did this; nor if the assessors were aware of the pa- } \\
\text { tients allocation status }\end{array}$ \\
\hline $\begin{array}{l}\text { Incomplete outcome data } \\
\text { (attrition bias) } \\
\text { All outcomes }\end{array}$ & Low risk & All enrolled patients were accounted for in the results \\
\hline $\begin{array}{l}\text { Selective reporting (re- } \\
\text { porting bias) }\end{array}$ & Low risk & Results for all expected outcomes were reported \\
\hline Other bias & Unclear risk & No baseline data were reported. No competing interests reported \\
\hline
\end{tabular}


Segal 2002

\begin{tabular}{ll}
\hline Methods & $\begin{array}{l}\text { Study type: single-centre RCT } \\
\text { Follow-up period: } 6 \text { weeks }\end{array}$ \\
\hline Participants & People at high risk undergoing cardiac surgery \\
\hline Interventions & lodine-impregnated adhesive plastic incisional drapes compared with no incisional drapes \\
\hline Outcomes & $\begin{array}{l}\text { Surgical wound infection. No clear definition of infection but included drainage, redness, tenderness or } \\
\text { instability }\end{array}$ \\
\hline Notes &
\end{tabular}

\section{Risk of bias}

\begin{tabular}{lll}
\hline Bias & Authors' judgement & Support for judgement \\
\hline $\begin{array}{l}\text { Random sequence genera- } \\
\text { tion (selection bias) }\end{array}$ & Low risk & $\begin{array}{l}\text { Pieces of paper marked with equal numbers of the different allocations were } \\
\text { placed in a sack }\end{array}$ \\
\hline $\begin{array}{l}\text { Allocation concealment } \\
\text { (selection bias) }\end{array}$ & Low risk & $\begin{array}{l}\text { When an eligible patient was identified, a piece of paper containing the alloca- } \\
\text { tion was drawn out of the sack by the operating room Charge Nurse }\end{array}$ \\
\hline $\begin{array}{l}\text { Blinding (performance } \\
\text { bias and detection bias) } \\
\text { All outcomes }\end{array}$ & High risk & $\begin{array}{l}\text { Masking was impossible for surgeons } \\
\text { It is unclear if patients were aware of their group allocation } \\
\text { The person assessing the outcome was aware of the patient's allocation group }\end{array}$ \\
\hline $\begin{array}{l}\text { Incomplete outcome data } \\
\text { (attrition bias) } \\
\begin{array}{l}\text { All outcomes } \\
\hline\end{array}\end{array}$ & Low risk & All enrolled patients were followed up \\
\hline
\end{tabular}

\begin{tabular}{lll}
\hline $\begin{array}{l}\text { Selective reporting (re- } \\
\text { porting bias) }\end{array}$ & Low risk & Results for all expected outcomes were reported \\
\hline Other bias & Low risk & $\begin{array}{l}\text { Patients equal at baseline for risk factors (communication with authors). No } \\
\text { competing interests }\end{array}$ \\
\hline
\end{tabular}

\section{Ward 2001}

\begin{tabular}{ll}
\hline Methods & $\begin{array}{l}\text { Study type: single-centre RCT } \\
\text { Follow-up period: } 5 \text { days }\end{array}$ \\
\hline Participants & Women undergoing caesarean section \\
\hline Interventions & $\begin{array}{l}\text { Incise (Smith \& Nephew) adhesive plastic incisional drapes compared with no adhesive plastic incision- } \\
\text { al drapes }\end{array}$ \\
\hline Outcomes & $\begin{array}{l}\text { Surgical wound infection (defined as having to include } 2 \text { of the following: erythema around sutures or } \\
\text { wound edge; seropurulent discharge from the wound; positive swab culture) } \\
\text { Number of days in hospital }\end{array}$ \\
\hline
\end{tabular}

\section{Notes}

\section{Risk of bias}

\section{Bias \\ Authors' judgement Support for judgement}

Use of plastic adhesive drapes during surgery for preventing surgical site infection (Review) 
Ward 2001 (Continued)

\begin{tabular}{lll}
$\begin{array}{l}\text { Random sequence genera- } \\
\text { tion (selection bias) }\end{array}$ & Low risk & Random number table \\
\hline $\begin{array}{l}\text { Allocation concealment } \\
\text { (selection bias) }\end{array}$ & Low risk & Allocation contained in opaque unmarked envelope
\end{tabular}

(selection bias)

Blinding (performance $\quad$ Low risk
bias and detection bias)

All outcomes

\author{
Masking was impossible for surgeons \\ Patients were blind to their allocation as the drape was placed after anaes- \\ thetic induction \\ Outcome assessment was blinded, postoperative care was provided by staff \\ unrelated to surgery
}

\begin{tabular}{lll}
\hline $\begin{array}{l}\text { Incomplete outcome data } \\
\text { (attrition bias) } \\
\text { All outcomes }\end{array}$ & Low risk & $\begin{array}{l}\text { Of the } 620 \text { patients randomised, } 15 \text { (2.4\%) had critical data missing from their } \\
\text { records and a further two patients were excluded, one for an existing infection } \\
\text { and one for early discharge }\end{array}$ \\
\hline $\begin{array}{l}\text { Selective reporting (re- } \\
\text { porting bias) }\end{array}$ & Low risk & Results for all expected outcomes were reported \\
\hline Other bias & Unclear risk & $\begin{array}{l}\text { Patients were only followed up for } 5 \text { days; some infections would have oc- } \\
\text { curred after this time. Baseline risk factors were equally distributed between } \\
\text { groups }\end{array}$ \\
\hline
\end{tabular}

Characteristics of excluded studies [ordered by study ID]

\begin{tabular}{|c|c|}
\hline Study & Reason for exclusion \\
\hline Breitner 1986 & Not a RCT \\
\hline Duvvi 2005 & Not a RCT \\
\hline Fairclough 1986 & Not a RCT \\
\hline Falk-Brynhildsen 2013a & Did not report wound infection rate \\
\hline French 1976 & Did not report wound infection rate \\
\hline Ha'eri 1983 & Did not report wound infection rate \\
\hline Lewis 1984 & Number of participants in each treatment arm not reported \\
\hline Manncke 1984 & Did not report wound infection rate \\
\hline Maxwell 1969 & Not a RCT \\
\hline Nystrom 1980 & Plastic incisional drape not used \\
\hline Nystrom 1984 & Plastic incisional drape not used \\
\hline Swenson 2008 & Not a RCT \\
\hline Williams 1972 & Plastic incisional drape not used \\
\hline Yoshimura 2003 & Not a RCT \\
\hline
\end{tabular}


$\mathrm{RCT}$ : randomised controlled trial

\section{DATA AND ANALYSES}

Comparison 1. Adhesive drapes versus no adhesive drapes

\begin{tabular}{|c|c|c|c|c|}
\hline Outcome or subgroup title & No. of studies & $\begin{array}{l}\text { No. of partici- } \\
\text { pants }\end{array}$ & Statistical method & Effect size \\
\hline $\begin{array}{l}1 \text { Surgical site infection (all } \\
\text { wound classifications) }\end{array}$ & 5 & 3082 & Risk Ratio (M-H, Fixed, 95\% Cl) & $1.23[1.02,1.48]$ \\
\hline $\begin{array}{l}2 \text { Surgical site infection (by } \\
\text { wound classification) }\end{array}$ & 1 & 921 & Risk Ratio (M-H, Fixed, 95\% Cl) & $1.20[0.86,1.66]$ \\
\hline 2.1 Clean & 1 & 363 & Risk Ratio (M-H, Fixed, 95\% Cl) & $1.37[0.53,3.53]$ \\
\hline 2.2 Potentially infected & 1 & 486 & Risk Ratio (M-H, Fixed, 95\% Cl) & $1.24[0.80,1.92]$ \\
\hline 2.3 Infected & 1 & 72 & Risk Ratio (M-H, Fixed, 95\% Cl) & $1.03[0.60,1.75]$ \\
\hline 3 Length of hospital stay & 1 & & Mean Difference (IV, Fixed, 95\% CI) & Totals not selected \\
\hline 3.1 Infected wound & 1 & & Mean Difference (IV, Fixed, 95\% CI) & $0.0[0.0,0.0]$ \\
\hline 3.2 No infected wound & 1 & & Mean Difference (IV, Fixed, 95\% CI) & $0.0[0.0,0.0]$ \\
\hline
\end{tabular}

Analysis 1.1. Comparison 1 Adhesive drapes versus no adhesive drapes, Outcome 1 Surgical site infection (all wound classifications).

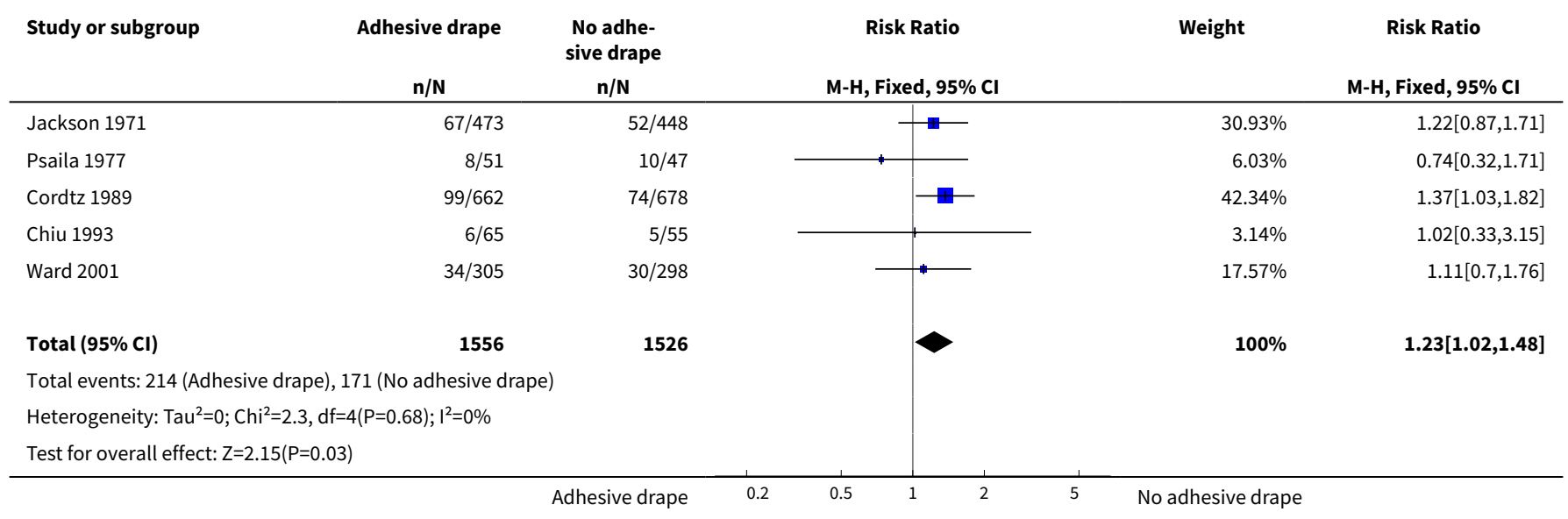


Analysis 1.2. Comparison 1 Adhesive drapes versus no adhesive drapes, Outcome 2 Surgical site infection (by wound classification).

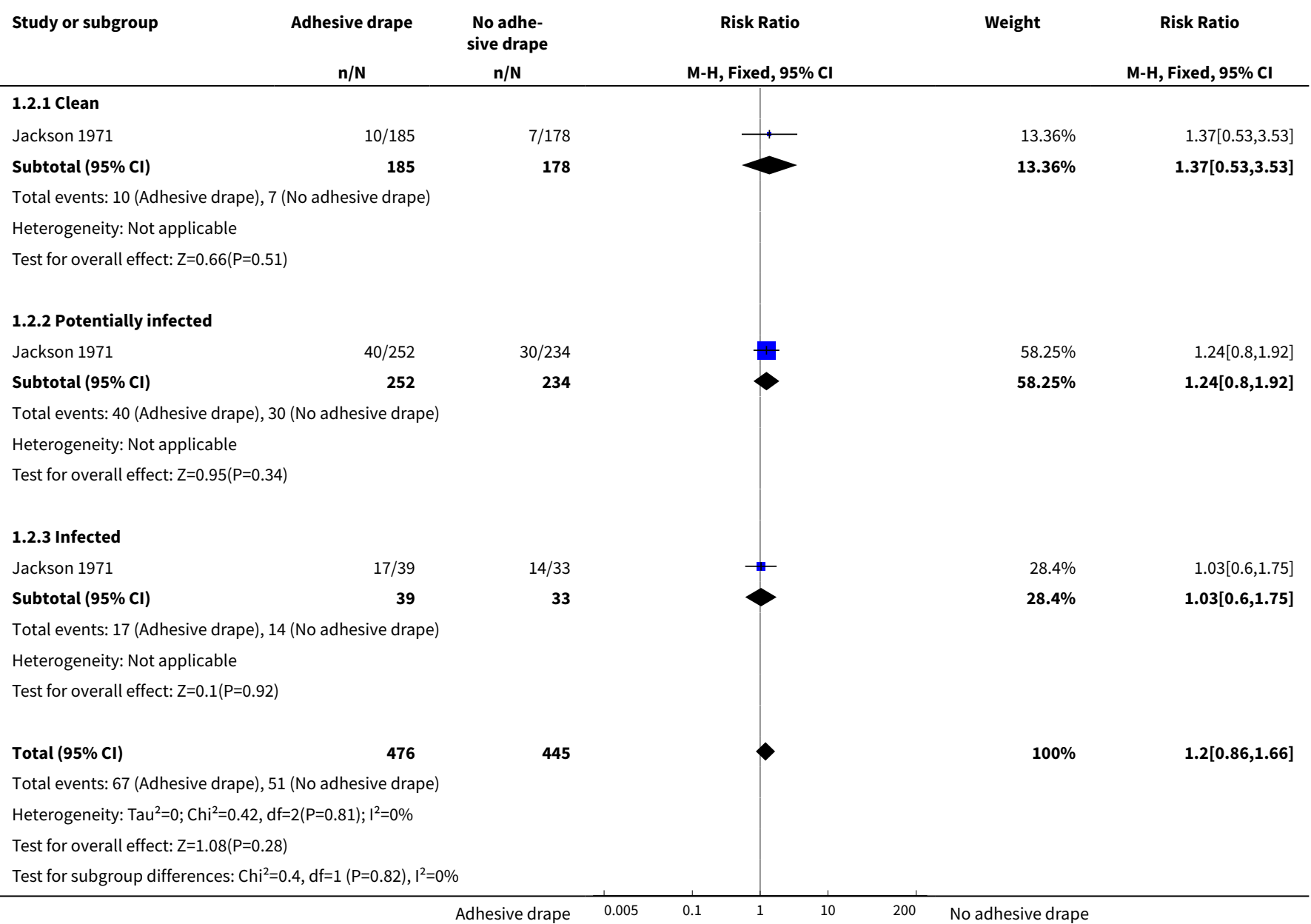

Analysis 1.3. Comparison 1 Adhesive drapes versus no adhesive drapes, Outcome 3 Length of hospital stay.

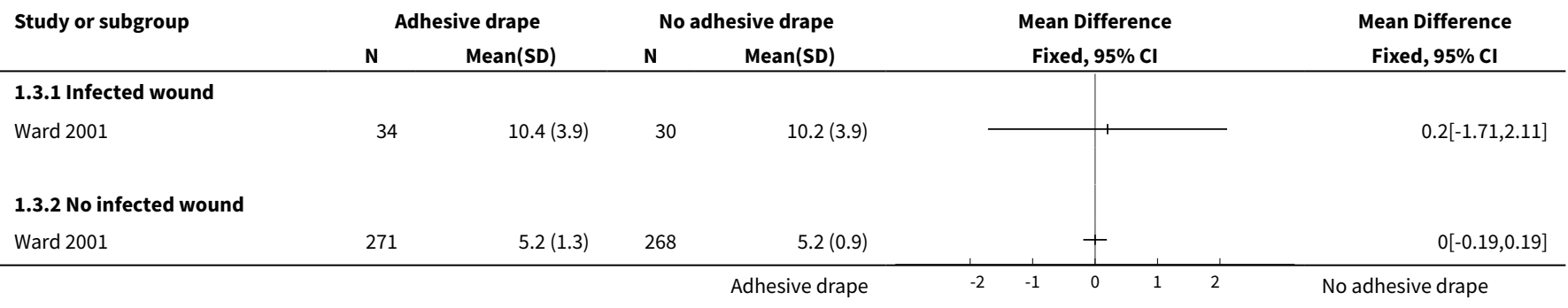

Comparison 2. lodine-impregnated adhesive drapes versus no adhesive drapes

\begin{tabular}{lllll}
\hline Outcome or subgroup title & No. of studies & $\begin{array}{l}\text { No. of partici- } \\
\text { pants }\end{array}$ & Statistical method & Effect size \\
\hline 1 Surgical site infection & 2 & 1113 & Risk Ratio (M-H, Fixed, 95\% Cl) & $1.03[0.66,1.60]$ \\
\hline \hline
\end{tabular}




\section{Analysis 2.1. Comparison 2 lodine-impregnated adhesive drapes versus no adhesive drapes, Outcome 1 Surgical site infection.}

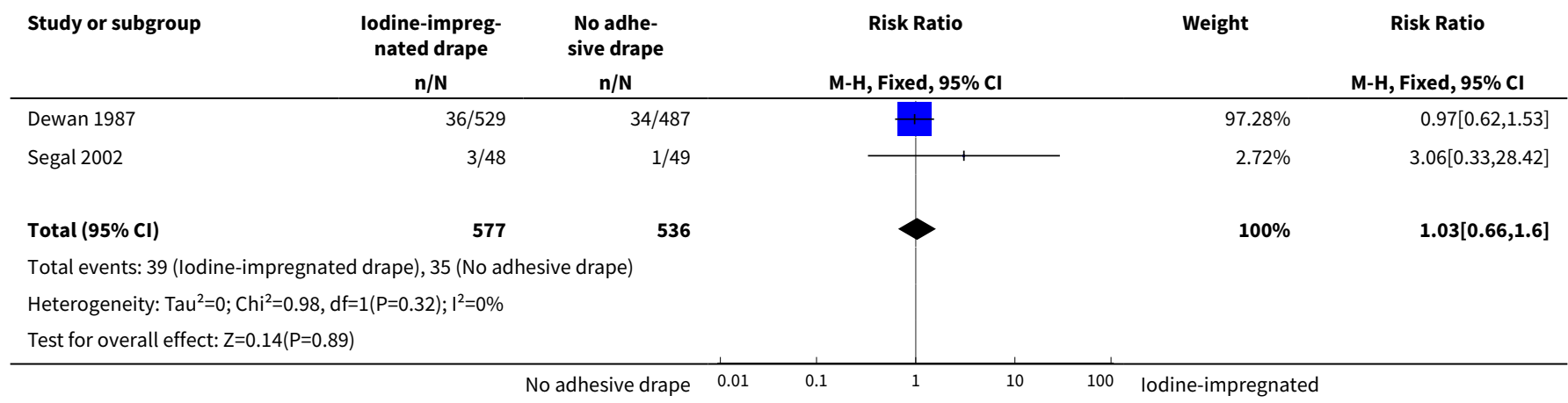

\section{A P P E N D I CES}

\section{Appendix 1. Search strategy for the third review update - 2012}

For this third update we modified the search strategy and ran it over all available years in the following electronic databases.

- The Cochrane Wounds Group Specialised Register (searched 19 July, 2012).

- The Cochrane Central Register of Controlled Trials (CENTRAL) (The Cochrane Library 2012, Issue 7).

- Ovid MEDLINE (1946 to July Week 2 2012).

- Ovid MEDLINE (In-Process \& Other Non-Indexed Citations, July 18, 2012).

- Ovid EMBASE (1974 to Week 28, 2012).

- EBSCO CINAHL (1982 to July 6, 2012).

We searched The Cochrane Central Register of Controlled Trials (CENTRAL) using the following strategy.

\#1 MeSH descriptor Surgical Wound Infection explode all trees

\#2 MeSH descriptor Surgical Wound Dehiscence explode all trees

\#3 MeSH descriptor Infection Control explode all trees

\#4 surg* NEAR/5 infection*

\#5 surg* NEAR/5 wound*

\#6 wound $^{*}$ NEAR/5 infection*

$\# 7$ (postoperative or post-operative) NEAR/5 infection*

\#8 (\#1 OR \#2 OR \#3 OR \#4 OR \#5 OR \#6 OR \#7)

\#9 plastic NEAR/3 drape*:ti,ab,kw

\#10 adhes ${ }^{\star}$ NEAR/3 drape* :ti,ab,kw

\#11 skin NEAR/3 drape* :ti,ab,kw

\#12 incis ${ }^{\star}$ NEAR/3 drape*:ti,ab,kw

\#13 iodophor NEAR/3 drape*:ti,ab,kw

\#14 iodine NEAR/3 drape* ${ }^{\star}$ ti,ab,kw

\#15 opsite or steridrape or ioban:ti,ab,kw

\#16 (\#9 OR \#10 OR \#11 OR \#12 OR \#13 OR \#14 OR \#15)

\#17 (\#8 AND \#16)

The search strategies for Ovid MEDLINE, Ovid EMBASE and EBSCO CINAHL can be found in Appendix 2, Appendix 3 and Appendix 4 respectively. We combined the Ovid MEDLINE search with the Cochrane Highly Sensitive Search Strategy for identifying randomised trials in MEDLINE: sensitivity- and precision-maximising version (2008 revision); Ovid format. We combined the EMBASE and CINAHL searches with the trial filters developed by the Scottish Intercollegiate Guidelines Network (SIGN). We did not apply any date or language restrictions.

\section{Appendix 2. Ovid MEDLINE search strategy}

1 exp Surgical Wound Infection/

2 exp Surgical Wound Dehiscence/ 
3 exp Infection Control/

4 (surg* adj5 infection $\left.{ }^{\star}\right)$.tw.

5 ( surg $^{\star}$ adj5 wound $\left.{ }^{\star}\right)$.tw.

6 ( surg $^{\star}$ adj 5 site $\left.{ }^{\star}\right)$. tw.

7 (surg ${ }^{\star}$ adj5 incision*).tw.

8 ( surg $^{\star}$ adj5 dehisc $\left.{ }^{\star}\right) . t w$.

9 (wound $^{*}$ adj5 dehisc $\left.{ }^{\star}\right)$.tw.

10 wound complication*.tw.

11 or/1-10

12 (plastic adj3 drape ${ }^{\star}$ ).tw.

13 (adhes $^{\star}$ adj3 drape*).tw.

14 (skin adj3 drape*).tw.

15 (incis* adj3 drape $^{\star}$ ).tw.

16 (iodophor adj3 drape*).tw.

17 (iodine adj3 drape ${ }^{\star}$ ).tw.

18 (opsite or steridrape or ioban).tw.

19 or/12-18

2011 and 19

\section{Appendix 3. Ovid EMBASE search strategy}

1 exp Surgical Wound Infection/

2 exp Surgical Wound Dehiscence/

3 exp Infection Control/

4 (surg $^{\star}$ adj5 infection $\left.{ }^{\star}\right)$.tw.

5 (surg $^{\star}$ adj 5 wound $\left.{ }^{\star}\right)$. tw.

6 ( surg $^{\star}$ adj5 site $\left.{ }^{\star}\right)$. tw.

7 (surg $^{\star}$ adj5 incision*).tw.

$8\left(\right.$ surg $^{\star}$ adj5 dehisc $\left.{ }^{\star}\right)$.tw.

9 (wound $^{\star}$ adj5 dehisc $\left.{ }^{\star}\right)$. tw.

10 wound complication ${ }^{\star}$.tw.

11 or/1-10

12 (plastic adj3 drape*).tw.

13 (adhes $^{\star}$ adj3 drape ${ }^{\star}$ ).tw.

14 (skin adj3 drape*).tw.

15 (incis $^{\star}$ adj3 drape ${ }^{\star}$ ).tw.

16 (iodophor adj3 drape*).tw.

17 (iodine adj3 drape ${ }^{\star}$ ).tw.

18 (opsite or steridrape or ioban).tw.

19 or/12-18

2011 and 19

\section{Appendix 4. EBSCO CINAHL search strategy}

S20 S11 and S20

$\mathrm{S} 19 \mathrm{~S} 12$ or $\mathrm{S} 13$ or $\mathrm{S} 14$ or $\mathrm{S} 15$ or $\mathrm{S} 16$ or $\mathrm{S} 17$ or $\mathrm{S} 18$ or $\mathrm{S} 19$

$\mathrm{S} 18 \mathrm{TI}$ (opsite or steridrape or ioban) or $\mathrm{AB}$ (opsite or steridrape or ioban)

S17 TI iodine N3 drape* or AB iodine N3 drape*

S16 TI iodophor ${ }^{\star}$ N3 drape* or AB iodophor ${ }^{\star}$ N3 drape*

S15 Tl incis ${ }^{\star}$ N3 drape* or AB incis* N3 drape*

S14 TI skin N3 drape* or AB skin N3 drape*

S13 TI adhes* N3 drape* or AB adhes* N3 drape*

S12 TI plastic N3 drape* or AB plastic N3 drape*

$\mathrm{S} 11 \mathrm{~S} 1$ or S2 or S3 or S4 or S5 or S6 or S7 or S8 or S9 or S10

S10 TI wound complication* or AB wound complication*

S9 TI wound* N5 dehisc* or AB wound ${ }^{*}$ N5 dehisc*

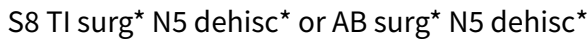

S7 Tl surg ${ }^{\star}$ N5 incision* or AB surg* N5 incision ${ }^{\star}$

S6 TI surg* N5 site* or AB surg* N5 site*

S5 TI surg* N5 wound ${ }^{\star}$ or AB surg* N5 wound ${ }^{\star}$

S4 TI surg* N5 infection* or AB surg* N5 infection*

S3 (MH "Infection Control+")

S2 (MH "Surgical Wound Dehiscence") 
S1 (MH "Surgical Wound Infection")

\section{Appendix 5. Risk of bias assessment definitions}

\section{Was the allocation sequence randomly generated?}

\section{Low risk of bias}

The investigators describe a random component in the sequence generation process such as: referring to a random number table; using a computer random number generator; coin tossing; shuffling cards or envelopes; throwing dice; drawing of lots.

\section{High risk of bias}

The investigators describe a non-random component in the sequence generation process. Usually, the description would involve some systematic, non-random approach, for example: sequence generated by odd or even date of birth; sequence generated by some rule based on date (or day) of admission; sequence generated by some rule based on hospital or clinic record number.

\section{Unclear}

Insufficient information about the sequence generation process to permit judgement of low or high risk of bias.

\section{Was the treatment allocation adequately concealed?}

\section{Low risk of bias}

Participants and investigators enrolling participants could not foresee assignment because one of the following, or an equivalent method, was used to conceal allocation: central allocation (including telephone, web-based and pharmacy-controlled randomisation); sequentially-numbered drug containers of identical appearance; sequentially-numbered, opaque, sealed envelopes.

\section{High risk of bias}

Participants or investigators enrolling participants could possibly foresee assignments and thus introduce selection bias, such as allocation based on: using an open random allocation schedule (e.g. a list of random numbers); assignment envelopes were used without appropriate safeguards (e.g. if envelopes were unsealed or non opaque or not sequentially numbered); alternation or rotation; date of birth; case record number; any other explicitly unconcealed procedure.

\section{Unclear}

Insufficient information to permit judgement of low or high risk of bias. This is usually the case if the method of concealment is not described or not described in sufficient detail to allow a definite judgement, for example if the use of assignment envelopes is described, but it remains unclear whether envelopes were sequentially numbered, opaque and sealed.

\section{Blinding - was knowledge of the allocated interventions adequately prevented during the study?}

\section{Low risk of bias}

Any one of the following.

- No blinding, but the review authors judge that the outcome and the outcome measurement are not likely to be influenced by lack of blinding.

- Blinding of participants and key study personnel ensured, and unlikely that the blinding could have been broken.

- Either participants or some key study personnel were not blinded, but outcome assessment was blinded and the non-blinding of others unlikely to introduce bias.

\section{High risk of bias}

Any one of the following.

- No blinding or incomplete blinding, and the outcome or outcome measurement is likely to be influenced by lack of blinding.

- Blinding of key study participants and personnel attempted, but likely that the blinding could have been broken.

- Either participants or some key study personnel were not blinded, and the non-blinding of others likely to introduce bias.

\section{Unclear}

Any one of the following.

- Insufficient information to permit judgement of low or high risk of bias.

- The study did not address this outcome. 


\section{Were incomplete outcome data adequately addressed?}

\section{Low risk of bias}

Any one of the following.

- No missing outcome data.

- Reasons for missing outcome data unlikely to be related to true outcome (for survival data, censoring unlikely to be introducing bias).

- Missing outcome data balanced in numbers across intervention groups, with similar reasons for missing data across groups.

- For dichotomous outcome data, the proportion of missing outcomes compared with observed event risk not enough to have a clinically relevant impact on the intervention effect estimate.

- For continuous outcome data, plausible effect size (difference in means or standardised difference in means) among missing outcomes not enough to have a clinically relevant impact on observed effect size.

- Missing data have been imputed using appropriate methods.

\section{High risk of bias}

Any one of the following.

- Reason for missing outcome data likely to be related to true outcome, with either imbalance in numbers or reasons for missing data across intervention groups.

- For dichotomous outcome data, the proportion of missing outcomes compared with observed event risk enough to induce clinically relevant bias in intervention effect estimate.

- For continuous outcome data, plausible effect size (difference in means or standardised difference in means) among missing outcomes enough to induce clinically relevant bias in observed effect size.

- 'As-treated' analysis done with substantial departure of the intervention received from that assigned at randomisation.

- Potentially inappropriate application of simple imputation.

\section{Unclear}

Any one of the following.

- Insufficient reporting of attrition/exclusions to permit judgement of low or high risk of bias (e.g. number randomised not stated, no reasons for missing data provided).

- The study did not address this outcome.

\section{Are reports of the study free of suggestion of selective outcome reporting?}

\section{Low risk of bias}

Any of the following.

- The study protocol is available and all of the study's prespecified (primary and secondary) outcomes that are of interest in the review have been reported in the prespecified way.

- The study protocol is not available but it is clear that the published reports include all expected outcomes, including those that were prespecified (convincing text of this nature may be uncommon).

\section{High risk of bias}

Any one of the following.

- Not all of the study's prespecified primary outcomes have been reported.

- One or more primary outcome(s) is reported using measurements, analysis methods or subsets of the data (e.g. subscales) that were not prespecified.

- One or more reported primary outcomes were not prespecified (unless clear justification for their reporting is provided, such as an unexpected adverse effect).

- One or more outcomes of interest in the review are reported incompletely so that they cannot be entered in a meta-analysis.

- The study report fails to include results for a key outcome that would be expected to have been reported for such a study.

\section{Unclear}

Insufficient information to permit judgement of low or high risk of bias. It is likely that the majority of studies will fall into this category. 


\section{Other sources of potential bias}

\section{Low risk of bias}

The study appears to be free of other sources of bias.

\section{High risk of bias}

There is at least one important risk of bias. For example, the study:

- had a potential source of bias related to the specific study design used; or

- had extreme baseline imbalance; or

- has been claimed to have been fraudulent; or

- had some other problem.

\section{Unclear}

There may be a risk of bias, but there is either:

- insufficient information to assess whether an important risk of bias exists; or

- insufficient rationale or evidence that an identified problem will introduce bias.

\section{FEE D B A C K}

\section{Feedback submitted by a representative of the Association of periOperative Registered Nurses (AORN), 19 March 2013}

\section{Summary}

Comment: Hello,

I am sending this message as a representative of the Association of periOperative Registered Nurses (AORN). We have provided a recommendation for our members based on the conclusion of a Cochrane systematic review with meta analysis. The methodology and conclusions of the researchers are being challenged. We would respectfully request a response regarding the questions posed.

AORN is a nonprofit membership association that represents the professional interests of more than 160,000 perioperative nurses by providing nursing education, standards, and clinical practice resources to enable optimal outcomes for patients undergoing operative and other invasive procedures. AORN's 40,000 registered nurse members manage, teach, and practice perioperative nursing, are enrolled in nursing education, or are engaged in perioperative research.

Each year, AORN publishes its Perioperative Standards and Recommended Practices. AORN's recommended practices represent what is believed to be optimal and achievable perioperative nursing practice and are based on the highest level of evidence available. The recommended practices describe excellent perioperative nursing practices, promote patient and health care worker safety, and guide policy and procedure development in surgical and invasive procedure settings.

Each recommended practices document focuses on a specific question or topic. The evidence review begins with a systematic literature search conducted using the databases MEDLINE ${ }^{\circledR}, \mathrm{CINAHL}^{\circledR}, \mathrm{Scopus}^{\circledR}$, and the Cochrane Database of Systematic Reviews for meta-analyses, randomized and nonrandomized trials and studies, systematic and nonsystematic reviews, and opinion documents and letters to identify articles related to the topic. The search is conducted by a medical librarian employed by AORN. As relevant studies are located, they are independently evaluated and critically appraised according to the strength and quality of the evidence using the Johns Hopkins EvidenceBased Practice Model Evidence Appraisal tools, adapted with permission for use in the AORN Authoring System ${ }^{\mathrm{TM}}$. The reviewers participate in conference calls to discuss the appraisal scores and to establish consensus. Each article or study is assigned an appraisal score as agreed on by the reviewers. The appraisal scores of individual references are noted in brackets after the citations in the references section of the RP document, as applicable.

After the studies are appraised, the collective evidence supporting each intervention within a specific recommendation is rated using the Oncology Nursing Society Putting Evidence into Practice ${ }^{\circledR}$ schema. Factors considered in review of collective evidence are the quality of research, quantity of similar studies on a given topic, and consistency of results supporting a recommendation.

In our 2013 AORN "Recommended practices for sterile technique," the following recommendation was made:

- Plastic adhesive incise drapes should not be used.

In a systematic review of seven randomized, controlled studies involving 4,195 patients, researchers concluded there was no evidence to support the use of plastic adhesive incise drapes as a method for reducing infection, and that there was some evidence that infection 
rates may be increased when adhesive incise drapes are used. A meta-analysis of five studies included in the review, which included 3,082 participants, compared plain plastic adhesive incise drapes with no drape and showed a significantly higher number of patients developed a surgical site infection when the adhesive incise drape was used. There was no effect on surgical site infection rates according to a meta analysis of two additional studies, including 1,113 participants, which compared iodine impregnated plastic adhesive incise drapes with no drape. The researchers theorized that the patient's skin is not likely to be a primary cause of surgical site infection if it is properly disinfected, and they concluded that attempting to isolate the skin from the surgical wound is of no benefit and may create increased moisture and bacterial growth under adhesive drapes.

The following evidence was cited to support this recommendation:

Webster J, Alghamdi A. Use of plastic adhesive drapes during surgery for preventing surgical site infection. Cochrane Database Syst Rev. $2011 ; 1$.

We are aware that this Cochrane review was updated in 2013, with no new studies identified and the conclusions of the researchers remaining unchanged.

According to our AORN model for individual evidence appraisal, the 2011 systematic review with meta analysis received the highest possible score for quality and strength of evidence, and the collective body of evidence was judged by consensus to be sufficient for qualification as a recommendation for practice.

The AORN recommendation not to use the adhesive incise drapes has received criticism by those who claim that the Cochrane meta analysis was flawed for the following reasons:

1. Clear incise drapes and antimicrobial incise drapes were analyzed separately and have different flaws.

a. All clear incise drapes were included as one entity despite the fact that not all of the products analyzed in the report are available and that the only common feature of clear incise drapes made by different manufacturers is that they are clear. Any differences in performance as a consequence of production history, adhesive, chemistry, etc., were not considered. As a result, those questioning the recommendation believe the conclusion of the researchers that the clear incise drapes raise the risk of surgical site infection is incorrect.

2. The meta analysis on iodine containing drapes failed to isolate those cases where infections are influenced by the use of such a drape, i.e., clean and clean-contaminated cases from those where the drape is not of clear value, i.e., contaminated or dirty surgery. As a result, those questioning the recommendation believe the conclusion of the researchers is conceptually flawed.

a. Those questioning the recommendation believe the use of antimicrobial impregnated incise drapes is commonly restricted to surgical cases where the nominal surgical site infection rate is approximately $1 \%$; therefore, a randomized controlled trial would require in excess of 40,000 subjects.

3. The Cochrane review contradicts the clinical literature when speculating in the discussion that skin organisms do not cause surgical site infection.

4. The statistical methods used in the antimicrobial portion of the analysis are inconsistent with the Cochrane Collaboration methodology, in that simply combining data and summing results is an inappropriate method for analysis.

AORN would greatly appreciate Cochrane's review of and response to the criticisms outlined above. We have suggested that these individuals contact Cochrane directly; however, this is not likely to happen. We believe it is important for these questions to be addressed. AORN is dedicated to providing recommendations for perioperative practice that are a credible and indispensable resource to perioperative nurses and other members of the surgical team. The use of scientific evidence to support national recommendations about clinical decisions has become an expectation of perioperative health care professionals. Evidence based practice is an essential method of improving patient care by promoting decisions based on scientific evidence rather than on the opinion of the individual health care provider.

Thank you so much for your swift attention to the issues expressed in this message. We look forward to hearing from you in the near future. Please do not hesitate to call or write if you have any questions or need additional clarification.

I certify that I have no affiliations with or involvement in any organization or entity with a financial interest in the subject matter of my feedback.

\section{Reply}

\section{Response by the review author Joan Webster}

The limitations of this Cochrane review include:

1. The clinical studies included in the analysis were not powered to detect a reasonable difference in SSI rates. When studies are not powered to detect a difference in an outcome, the result is that even if there were a difference in SSI rate attributable to the adhesive drape, the studies would conclude that there was no difference. Adequate statistical power is critical because a false-negative result is a predictable consequence including an insufficient number of patients. For example, with a baseline SSI rate of $5 \%$ and a reasonable $20 \%$ reduction in SSI (to $4 \%$ ), 18,000 subjects are needed to provide $90 \%$ power. Consider the two iodophor-impregnated drape studies 
included in the Cochrane review; the minimum reduction of SSI rate required to detect an inter-group difference given the number of patients actually included is shown in Table 1.

Table 1. Sample Size of lodophor-Impregnated Drape Studies

\begin{tabular}{lllll}
\hline Study & $\mathrm{n}$ in Drape Group & $\begin{array}{l}\mathrm{n} \text { in Control } \\
\text { Group }\end{array}$ & $\begin{array}{l}\text { SSI rate in Control } \\
\text { Group }\end{array}$ & $\begin{array}{l}\text { SSI rate reduction needed to detect a difference, } \\
\text { given n (90\% power) }\end{array}$ \\
\hline Dewan 1987 & $392^{\star}$ & $354^{\star}$ & $5.6 \%$ & $70 \%$ reduction \\
\hline Segal 2002 & 51 & 50 & $0.25 \%$ & Not possible \\
\hline
\end{tabular}

${ }^{\star}$ For clean and clean-contaminated procedures

Segal et al is thus uninterpretable. Dewan et al would only detect a completely implausible $70 \%$ reduction in infection risk; from a practical perspective, it is also uninterpretable.

The same calculations can be made for the other five studies used for clear drapes. For four of the studies the reduction in SSI needed to detect a difference ranged from $45 \%$ to $95 \%$, and for one of the studies it was not possible to detect any difference. Thus, none of the clinical studies included in this Cochrane review was powered to detect a reasonable SSI difference.

According to the Evidence Level and Quality Guide in the Johns Hopkins Nursing Evidence-Based Practice: Model and Guidelines, Second Edition, 2012, Appendix C, these seven studies fall under Level I Evidence (randomized controlled trials or RCT), and a Quality level C "Low Quality or Major Flaws" due to "insufficient sample size for the study design; conclusions cannot be drawn."

Many individual studies included in Cochrane reviews are under-powered. The strength of meta analysis is the pooling of trials which individually may be underpowered but together increase statistical power. Moreover, because reviews are updated every 2 years, Cochrane reviews ensure that evidence is cumulative. Cochrane reviewers are committed to scientific rigor and ensuring that reviews are free of any conflicts of interest. Careful peer review, including statistical review, is undertaken before any review is published.

With respect, the authors of the feedback are making the mistake of confusing internal validity with statistical power. These are completely different issues; the former concerns whether the results of the study are likely to be $a$ true reflection of the effect of the intervention on the people in the study (or alternatively whether they reflect a bias in the design or method). Low statistical power does not introduce bias, but it reduces the precision of the estimate, so that one is less likely to detect a real treatment difference (if it exists) as statistically significant.

2. For both meta-analyses, clear and iodine-impregnated drapes, the definition of SSI was different among the studies, and the SSI data from all four wound classes was [sic] combined to determine the effect of incise drapes. This is conceptually flawed. There are four wound categories: clean, clean-contaminated, contaminated and dirty. Skin organisms are the major cause of SSI in clean and clean-contaminated surgeries ( 1) Mangram A et al. Guideline for the Prevention of Surgical Site Infection, 1999 The Hospital Infection Control Practices Advisory Committee Infect Control Hosp Epidemiol. Vol 20, No. 4, pp 247 - 278; and 2) Anderson D., Surgical Site Infections Infec Dis Clin N Am 25 (2011) 135-153), for which an incise drape may provide benefit by way of reducing microbial contamination of the wound and helping to maintain the sterile field. On the other hand, non-skin pathogens are the primary cause of SSIs for dirty and contaminated procedures.

The Cochrane review failed to distinguish among types of wound class and, to study the effect of adhesive drapes, pooled all the SSI data from all wound classes, which is conceptually flawed.

This is incorrect. Please see 'Analysis 1.2and 1.3: Adhesive drapes versus no adhesive drapes' in the updated review, which shows the surgical site infection rate by wound classification. No benefit of effect for plastic drapes was found in any category. Moreover, in Analysis 1.1, irrespective of wound category, the SSI rate was not statistically lower in the plastic drape group, in any study.

3. The clear adhesive incise drape meta-analysis pools SSI data from five studies that used a wide variety of clear incise drapes. There was no distinction among materials, manufacturing processes, adhesives, or important study design factors. For example, two of the studies used linen or cotton drapes which are known to allow fluid and microbial strike-through, two used drapes that are no longer available, and one remarkably did not even identify the drape used (Table 2). In fact, the only characteristic these clear adhesive incise drapes share is their transparency. Comparability in treatment and outcome are required for valid meta-analysis - a requirement that was unmet in this case.

Table 2 - Clear Adhesive Incise Drapes 


\begin{tabular}{|c|c|c|c|}
\hline Study Date & Author & Brand of Incise Drape & Other Drapes Used \\
\hline 1971 & Jackson & $\begin{array}{l}\text { Band-Aid Sterile Drapes (J\&J) Not on the } \\
\text { Market }\end{array}$ & $\begin{array}{l}\text { Cotton drapes were used which are } \\
\text { known to allow fluid and microbial } \\
\text { strike-through (No barrier function) }\end{array}$ \\
\hline 1989 & Cordtz & Brand Unknown & Not specified \\
\hline
\end{tabular}

1993

Opsite ${ }^{\mathrm{TM}}$ Incise Drapes by Smith and Nephew Not specified

(Old version; most likely no longer on the market)

$2001 \quad$ Ward

Opsite $^{\mathrm{TM}}$ Incise Drapes by Smith and Nephew (Study states, "a new version with better ad-

Not specified hesion")

This information is quite irrelevant. In fact, using the statement that: "Linen drapes were used which are known to allow fluid and microbial strike-through (No barrier function)", actually provides additional evidence for the failure of incise drapes. That is, plastic drapes could not be shown to be superior, even to these 'flawed' linen comparisons.

4. Five studies were included in the meta-analysis for clear incise drapes. The relative risk of surgical site infections was 1.23 (95\% $\mathrm{Cl} 1.02$ - 1.48) which is (barely) statistically significant. However, this purported risk traces to Cordtz et al. (1989), in which the authors specify that the rates of infection were "the same in draped patients and control." The Cochrane Collaboration's conclusion that adhesive drapes augment infection risk is supported by only a single study - from which even the authors did not conclude that risk was increased.

An important design feature of systematic reviews is the pre-specification of review methodology, including anticipation of major decisions (such as choice of cut-point for statistical significance) whilst still "blind" to study results (hence the publication of review protocols). We followed our pre-specified protocol and its decisions faithfully, our methods are transparent. The authors of the feedback seem to be implying that we should alter our pre-specified methods if we don't like the findings, or don't agree with the conclusions of individual studies. This would reflect a traditional approach to reviewing that introduces bias and we are keen to avoid it.

The five included trials represent a population of over 3,000 participants. A relative risk of 1.23 indicates a $23 \%$ higher risk of infection in the plastic drape group. This is quite an important difference. The review presents the data which speak for themselves; we do avoid (as per Cochrane Collaboration guidance) the use of rather biased and potentially misleading phrases such as "barely statistically significant"; "tending to statistical significance"; "almost statistically significant". It is not unusual to read a trial report where an author reports that the rates if infection were similar and then when the data presented in the report are analysed there is in fact a statistically significant difference. This is a strength of the independence and rigor of a Cochrane review.

5. Antimicrobial prophylaxis, serum glucose concentration, proper hair removal, and maintaining normothermia are important covariates that impact risk of SSI. In most studies, these issues were not even addressed, much less separately reported.

In randomized controlled trials these factors would be balanced across treatment groups; this is the advantage and strength of randomization.

In addition to these limitations, the authors of this Cochrane report conclude that: "a large, high

quality definite [sic] RCT may be warranted to determine whether modern adhesive drapes do prevent or reduce SSIs". Thus, even the Cochrane authors recognize that their conclusions are weak and do not constitute sufficient evidence to support a practice recommendation.

Our conclusion (that further research is needed) reflects the fact that the research in this field has shortcomings in volume and quality. However our conclusion that the available evidence does not suggest that plastic adhesive drapes reduce SSI rates still

\section{Contributors}

Sharon A. Van Wicklin, Perioperative Nursing Specialist, AORN (Association of periOperative Registered Nurses) Joan Webster, Nursing Director, Research. Centre for Clinical Nursing. Royal Brisbane and Women's Hospital. Brisbane, Queensland 


\section{Feedback from 3M, a manufacturer of plastic adhesive incise drapes, 11 April 2013}

\section{Summary}

Comment: It is the view of $3 \mathrm{M}$ that the Cochrane Review titled Use of plastic adhesive incise drapes for preventing surgical site infection published in 2007 and subsequently have been issued as meta-analysis. Since it was issued, the review should have critically highlighted the many shortcomings of the data, the absence of meaningful information, and the inability to determine the effect of incise drapes on surgical site infection rates. This Cochrane Review has recently had a significant impact on product use recommendations in the USA which may have far-reaching repercussions so $3 \mathrm{M}$ feels compelled to provide feedback at this time.

$3 \mathrm{M}$ has involved external experts (surgeons, biostatisticians, epidemiologists) to review the Cochrane Report and the seven clinical studies included and to provide honest, objective comments. Their consensus is that this Cochrane Review included studies that are flawed in many ways, making it unhelpful for policy.

The key flaws can be summarized as follows:

1. Failure in all studies to control for confounding

2. Likelihood of bias

3. Absence of power estimates, and thus, potential for type II errors

4. Heterogeneity of the study populations, definition of primary endpoint (infections) and incise drapes that seem to preclude a metaanalysis

5. The broad time span of the studies included and the absence of data on over a decade make the conclusions unuseful for the current medical practice

$3 \mathrm{M}$ does acknowledge that there is a compelling need to conduct further clinical studies to demonstrate the effect of plastic adhesive incise drapes on surgical site infection.

Since we could not find a way to attach a document in this feedback page, $3 \mathrm{M}$ respectfully requests the Cochrane Organization to provide a mechanism, i.e. an e-mail address, to submit a document that includes a detailed scientific review.

We appreciate in advance your attention to this matter and we look forward to hearing from your soon.

I have modified the conflict of interest statement below to declare my interests:

These comments are being provided on behalf of $3 \mathrm{M}$, a manufacturer of plastic adhesive incise drapes (with and without an antimicrobial agent) the subject of this Cochrane

This comments was accompanied by a pdf of a Technical Review of: WebsterJ, Alghamdi A. "Use of plastic adhesive drapes during surgery for preventing surgical site infection" The Cochrane Library, 2013

written by:

Michelle Hulse Stevens, MD, Medical Director and Chief Medical Officer, 3M Infection Prevention Division

Inmaculada Soria, Ph.D., Director, Clinical Affairs and Technical Service, 3M Infection Prevention Division

Nancy Klinger, Manager, Clinical Affairs, 3M Infection Prevention Division

With consultation from:

Dan Sessler MD, Chair Department of Outcomes Research, Cleveland Clinic

Richard Wenzel, MD, MSc., Professor and Former Chairman, Department Internal Medicine,Virginia Commonwealth University

\section{It was not possible to include a copy of this report in this section of the review but a copy can be obtained from the Cochrane Wounds} Group editorial base.

\section{Reply}

Response by the Statistical Editor of the Cochrane Wounds Group

With respect to the comments from $3 \mathrm{M}$ :

I don't think the Cochrane review is flawed, it followed the recommended methods. It is the studies contained within the review which are flawed, not the actual review. None of their 5 main points refer to the review methods, they all relate to either the methods of the studies or the evidence as a whole (in terms of heterogeneity and the wide time span).

1. Confounding: this isn't a problem. The review only included randomised controlled trials, as these have been randomised all known and unknown confounders should be balanced between the groups. There is no need to perform any matching, stratified or multivariate analysis. Matching would be inappropriate as is not relevant to an RCT, only observational studies. The other analysis methods could be used, for example, to adjust for centre if the randomisation was stratified by centre, or to account for prognostic factors, maybe type of surgery. But they are not strictly necessary.

2. Bias: I am not clear what is meant by the first point which compared the earlier to the later studies. Both sets of studies are quite likely to contain the same flaws, and again confounding is not an issue. Failure to report the randomisation method and lack of blinding, yes, this is a problem with the studies. Lack of randomisation details is a common problem with reviews but it is not really a form of bias just poor reporting. For the blinding, due to the intervention they couldn't blind the surgeons. But could blind the outcome assessor. The review 
comments on this in the risk of bias assessment and only 2 trials had blinded outcome assessment. The conclusion in the abstract says that further trials are needed using blinded outcome assessment so I think this has been addressed in the review.

3. Type II errors. True this is a fair comment. This could have been commented on in the review but it wasn't. However the risk of bias tool used doesn't judge whether or not there was a sample size calculation, so it was not discussed in the risk of bias section. But this is a flaw with the studies, and it is a common one. I read a lot of papers and it is the minority which report a sample size calculation.

4. Heterogeneity. Type of surgery and wound class, yes, these are possible causes of heterogeneity and could have been included as subgroup analyses. The review states the planned subgroup analyses (although not necessarily performed due to a lack of data) and one of them was clean compared with contaminated surgery. This has been done, there are forest plots showing results grouped by wound classification. Type of surgery has not been looked at but the thing to note here is that the potential sources of heterogeneity / subgroup analyses should be prespecified in the protocol, and not just explored within the review (as the more subgroup analyses you do the more likely you are to find something). So as surgery type was not prespecified it must not have been thought to be a potential factor. Definition of infection, yes this varied, but that is what the studies reported so the review has to use what the studies say. However the question this review is addressing is the use of adhesive drapes versus not, to address the actual type of drape was not part of the question or the protocol. Which is why it hasn't been done (and one study didn't tell you anyway).

5. Broad time span. Yes this is a good point. It is a wide time frame and presumably things have changed quite a lot since 1971 . This could have been discussed more by the review. They do cover it briefly in terms of the changes in the product over 30 years but the points about antibiotic resistance of organisms could be added. It might also be useful to do a sensitivity analysis removing the 2 oldest studies to see how it changes the results.

Additional comments:

- Lack of reporting of bacteria and MRSA, single institutions, all fair comment.

- Increase in SSI, the results of analysis 1.1 do show this. Three of the five studies do show more SSI with the drapes although not statistically significant in 2 of them.

Conclusions.

The meta-analyses are not flawed. Some of the included studies were at moderate risk of bias, some were unclear for many aspects. This is covered by the discussion of the review. The review can only really discuss those aspects assessed by the risk of bias tool. It does highlight shortcomings in the evidence but aspects such as the power of the studies, and the materials and manufacturing processes of the drapes were outside the review's scope and not part of the protocol which is why they haven't been addressed.

\section{Comments by Professor J. Martin Bland, Professor of Health Statistics}

The critique raises five points:

1. Failure in all studies to control for confounding.

2. Likelihood of bias.

3. Absence of power estimates and thus the potential for type II errors.

4. Heterogeneity of the study populations, definition of primary endpoint (infections) and incise drapes that seem to preclude a metaanalysis.

5. The broad time span of the studies included and the absence of data in over a decade make the conclusions not useful for current medical practices.

\section{Failure in all studies to control for confounding.}

"Confounding" occurs when the outcome variable, infection, and the explanatory variable, drapes, are both related to a third, preexisting variable which affects the apparent relationship between them. Confounding should not occur in a randomised trial, because the randomised groups are from the same population. They should not differ in any way other than those arising by chance. The critics say:

"In no study was there matching on the front end, a stratified analysis on the back end or a multivariate analysis. Examples of such confounding variables include age, co-morbidities, obesity, serum glucose concentration, proper hair removal, normothermia, and receipt of antibiotics preoperatively and their timing relative to incisions. All of these important covariates impact the risk of SSI."

If there are covariates which are prognostic, related to the outcome variable, it is a good idea to adjust for them. This will improve the precision of estimates. This can only be done using the participant level data, so should be done by the original investigators. It is a feature of clinical trials that most of them could have been done better. If all trials were done to the highest standard, we would not need systematic reviews, but the world is not like that. The effect of not adjusting is to widen confidence intervals and increase P values. It does not invalidate or bias the trial; it makes it inefficient.

\section{Likelihood of bias.}


The critics say:

"If the initial 4 studies performed between 1971 and 1989 (3480 subjects), versus those from 1993 to 2001 (826 subjects), had errors (confounding issues or bias) in favor of no efficacy, bias would be likely."

There is no doubt that this is a true statement. This true statement does not imply that there is, in fact, any bias. As noted above, there should not be confounding in a randomised trial and failure to adjust for covariates does not produce bias. The critics also say:

"The failure to provide a recorded randomization method and the lack of blinding are both well known to lead to bias."

It is true that both of these are potential sources of bias. They do not necessarily lead to bias. General experience is that biases are usually in favour of the test treatment.

\section{Absence of power estimates and thus the potential for type II errors.}

The critics say:

"All seven studies in the meta-analyses were grossly underpowered and thus the ability to find a difference - if one existed - is negated, even in the meta analysis. None of the seven clinical studies included in the analyses were powered to detect a reasonable difference in SSI rates. Adequate statistical power is critical because a false-negative result is a predictable consequence of including an insufficient number of patients. For example, with a baseline SSI rate of $5 \%$ and a reasonable $20 \%$ reduction in SSI (to 4\%), 18,000 subjects are needed to provide 90\% power."

This calculation is correct. Many, if not most, randomised clinical trials are underpowered. However, when the trials have been carried out, we should not refuse to analyse them on these grounds. Systematic review was introduced to deal with just this problem and enables us to get the maximum amount of information from the inadequate data available. Confidence intervals, the preferred method to report results from trial, do not give us a yes or no answer but a range of plausible values for the treatment effect. In this review, for adhesive drapes the risk of SSI is estimated to be between 1.02 and 1.48 times the risk without adhesive drapes, which does not include the critics' postulated 0.80 , and for iodine impregnated adhesive drapes the risk of SSI is estimated to be between 0.66 and 1.60 times the risk without adhesive drapes, which does include the critics' postulated 0.80 . Thus we have good evidence that adhesive drapes increase the risk of infection, though possibly only by as much as $3 \%$, and that iodine impregnated adhesive drapes may reduce the risk of SSI by up to a third and may increase it by up to two-thirds.

Significance test approaches are not as informative. The fact that a particular study could not produce a significant difference alone does not mean it is not informative and interpretable in a meta-analysis.

\section{Heterogeneity of the study populations, definition of primary endpoint (infections) and incise drapes that seem to preclude a meta-analysis.}

There is certainly clinical heterogeneity between these studies. It may be that adhesive drapes work completely differently in different surgical procedures and using different wounds definitions, to the extent that an average effect is of no interest. If that is true, we would need very large trials separately for each type of surgery and each definition of infection. Is it plausible that the effect of adhesive drapes varies so much? This would make it very difficult to know when they could be used, in the absence of these trials. But surely while we wait for them we should make the best use of what data are currently available.

We could note that there is no evidence of statistical heterogeneity in SSI relative risk, though the clinical heterogeneity would certainly lead me to prefer a random effects model to be used. Using current methods, and the random effects and the fixed effect analyses will be identical. There is no statistical reason to suppose that the clinical heterogeneity produces heterogeneity of effects.

\section{The broad time span of the studies included and the absence of data in over a decade make the conclusions not useful for current medical practices.}

The authors say:

"The first study was performed 41 years ago and the last 31 years afterwards, and no studies were included for the last 11 years. This is problematic. The practices of medicine and surgery have changed greatly; infection control and quality of care have become more visible and more effective over the time span; standardized surveillance is more commonplace now. The fact that there are no studies in over a decade during which time safety has emerged as a priority and guidelines have become more common and are more detailed suggest little relevance to practice today. Furthermore, the organisms causing infections have changed over 41 years and become more antibiotic resistant, prompting some changes in perioperative prophylaxis."

While this is true, should we need to keep randomising people to treatments where there has been past evidence of harm, in case things have changed? We can only analyse the data available and if we have a system where established effective treatments have to be continually retrialled, things will grind to a halt. 


\section{Additional Comments}

The critics say: "There was failure to show the spectrum of bacteria implicated in 6/7 studies. In the Chiu study with 14 SSIs, 8 were caused by MRSA (perioperative prophylaxis with an ineffective "cephalosporin"), suggesting a true problem at the hospital, such as an outbreak, and opportunity for co-founding in the study."

The point that the spectrum of bacteria implicated might have been informative is a valid one, but there is nothing that reviewers can do about this.

The critics say: "Six of the seven studies were performed in a single institution making generalization problematic." By looking at the studies combined, a greater variety of settings is studied, which is a strength of systematic review. This point is nonsensical.

The critics say: "The Cochrane Review authors concluded was that there was some evidence that plastic adhesive incise drapes increase infection rates, but there is no such evidence. Five studies were included in the meta-analysis for clear incise drapes. The relative risk of surgical site infections was 1.23 (95\% Cl 1.02 - 1.48) which is (barely) statistically significant. However, this purported risk traces to Cordtz et al. (1989), in which the authors specify that the rates of infection were "the same in draped patients and control." The Cochrane Collaboration's conclusion that adhesive drapes augment infection risk is supported by only a single study - from which even the authors did not conclude that risk was increased."

The confidence interval would certainly convince me that the evidence is that adhesive drapes do not reduce infection. It does not depend on one study alone; four of the five studies have a point estimate of the relative risk greater than 1.00 and the fifth is the smallest study in terms of numbers randomised. That Cordtz et al. choose to interpret "not significant" as "the same" is not the fault of reviewers. This is a very common misunderstanding among clinical researchers.

\section{Response by the review author Joan Webster}

\section{OBJECTIVE}

The objective of this review is to evaluate the limitations of the Cochrane Review titled "Use of plastic adhesive drapes during surgery for preventing surgical site infection".

\section{REVIEW}

The Cochrane review consisted of two meta-analyses that assessed the effect of adhesive incise drapes on surgical site infection (SSI) rates:

1. Five trials with the use of clear adhesive incise drapes (non-antimicrobial)

2. Two trials with the use of iodine-impregnated adhesive incise drapes.

This Cochrane review is flawed in many ways and the key limitations are summarized below and are also presented in tabular form in the Appendix.

1. Failure in all studies to control for confounding.

2. Likelihood of bias.

3. Absence of power estimates and thus the potential for type II errors.

4. Heterogeneity of the study populations, definition of primary endpoint (infections) and incise drapes that seem to preclude a metaanalysis.

5. The broad time span of the studies included and the absence of data in over a decade make the conclusions not useful for current medical practices.

1. Confounding. In no study was there matching on the front end, a stratified analysis on the back end or a multivariate analysis. Examples of such confounding variables include age, co-morbidities, obesity, serum glucose concentration, proper hair removal, normothermia, and receipt of antibiotics preoperatively and their timing relative to incisions. All of these important covariates impact the risk of SSI.

We agree that certain risk factors will impact on an individuals' risk of acquiring a SSI. However, this Cochrane review only included RCTs, which by definition do not experience confounding (if randomisation is properly conducted-hence the importance of Risk of Bias Assessment).

In the current review, no baseline data were reported for the studies of Cordez (1989), Jackson (1971) or Psaila (1977). Whereas Chiu (1993), Dewan (1987), Segal (2002) and Ward (2001) all indicated that patients were matched for all relevant risk factors at baseline.

\section{Bias.}

- If the initial 4 studies performed between 1971 and 1989 (3480 subjects), versus those from 1993 to 2001 (826 subjects), had errors (confounding issues or bias) in favor of no efficacy, bias would be likely.

- The failure to provide a recorded randomization method and the lack of blinding are both well known to lead to bias.

Please see above. All studies are assessed for their individual risk of bias in six domains (sequence generation, allocation concealment, blinding, completeness of outcome data, selective reporting, and other biases, such as baseline imbalance). In the table 
'Characteristics of included studies', shortcomings of each trial are reported against each of these criteria. Many trial reports, published before the CONSORT statement, failed to provide sufficient information to be able to judge the quality of the trials' conduct. Because of this, it is unclear, in many studies, if bias existed or not. It may have been the case that some requirements outlined in the CONSORT Statement may have been met but simply was not reported.

3. Type Il errors. All seven studies in the meta-analyses were grossly underpowered and thus the ability to find a difference - if one existed - is negated, even in the meta-analysis.

We agree with the feedback that the studies are underpowered, but they still contain information; the value of which is enhanced by meta-analysis (by increasing the power). The implied alternative is that we ignore all studies that were individually underpowered or had design flaws. That would consign most of all the medical research ever conducted to the waste bin.

Moreover, because reviews are updated every 2 years, Cochrane reviews ensure that evidence is cumulative. Cochrane reviewers are committed to scientific rigor and ensuring that reviews are free of any conflicts of interest. Careful peer review, including statistical review, is undertaken before any review is published.

4. Heterogeneity. Besides leading to confounding and bias, this aspect of the report usually precludes a meta-analysis. The most obvious issues include:

- Types of surgery: abdominal - general ( $\mathrm{N}=3)$, $\operatorname{cardiac}(\mathrm{N}=1), \mathrm{C}$-section $(\mathrm{N}=2)$, and hip surgery $(\mathrm{N}=1)$.

There was no statistical heterogeneity between studies ( $12=0 \%)$. In addition, all of the studies trended towards favouring the 'no drape' group (with the exception of the smallest study (Psaila 1977)

-Wound Class. The SSI data from all four wound classes were combined to determine the effect of incise drapes. This is conceptually flawed. There are four wound categories: clean, clean-contaminated, contaminated and dirty. Skin organisms are the major cause of SSI in clean and clean-contaminated surgeries $(1,2)$, for which an incise drape may provide benefit by way of reducing microbial contamination of the wound and helping to maintain the sterile field. On the other hand, non-skin pathogens are the primary cause of SSIs for dirty and contaminated procedures. The Cochrane review failed to distinguish among types of wound class and, to study the effect of adhesive drapes, pooled all the SSI data from all wound classes, which is conceptually flawed. This is incorrect. Please see 'Analysis 1.2and 1.3: Adhesive drapes versus no adhesive drapes' in the updated review, which shows the surgical site infection rate by wound classification. No benefit of effect for plastic drapes was found in any category. Moreover, in Analysis 1.1, irrespective of wound category, the SSI rate was not statistically lower in the plastic drape group, in any study.

Definition of Infection. The inconsistency of definitions for an infection is remarkable from very nonspecific definitions such as "tenderness" to a vague definition of "clinical evidence" to a more robust definition of "pus" - the single definition in two studies. As definitions of infections frequently vary between studies (and sometimes are absent) our inclusion criteria clearly stated that: "For the purposes of this review we accepted the definition of SSI used in the trial". This is a pragmatic, and we feel entirely defensible, approach.

Clear Incise Drape Used. The clear adhesive incise drape meta-analysis pools SSI data from five studies that used a wide variety of clear incise drapes. There was no distinction among materials, manufacturing processes, adhesives, or important study design factors. For example, two of the studies used drapes that are no longer available, two of the studies used additionally linen or cotton drapes which are known to allow fluid and microbial strike-through, and one, remarkably, did not even identify the drape used (Table 2). In fact, the only characteristic these clear adhesive incise drapes share is their transparency. Comparability in treatment and outcome are required for valid meta-analysis - a requirement that was unmet in this case. This information is quite irrelevant. In fact, using the statement that: "Linen drapes were used which are known to allow fluid and microbial strike-through (No barrier function)", actually provides additional evidence for the failure of incise drapes. That is, plastic drapes could not be shown to be superior, even to these 'flawed' linen comparisons.

5. Broad time span. The first study was performed 41 years ago and the last 31 years afterwards, and no studies were included for the last 11 years. This is problematic. The practices of medicine and surgery have changed greatly; infection control and quality of care have become more visible and more effective over the time span; standardized surveillance is more commonplace now. The fact that there are no studies in over a decade during which time safety has emerged as a priority and guidelines have become more common and are more detailed suggest little relevance to practice today. Furthermore, the organisms causing infections have changed over 41 years and become more antibiotic resistant, prompting some changes in perioperative prophylaxis. Despite the time span, head to head comparisons between no adhesive plastic drape versus use of an adhesive plastic drape have consistently shown no advantage associated with adhesive drapes. We would be pleased to include information from independent clinical trials in any future update, Cochrane reviews are updated on average every two years but will be updated earlier in the light of substantial new evidence becoming available.

\section{Additional Comments}

There was failure to show the spectrum of bacteria implicated in $6 / 7$ studies. In the Chiu study with 14 SSIs, 8 were caused by MRSA (perioperative prophylaxis with an ineffective "cephalosporin"), suggesting a true problem at the hospital, such as an outbreak, and opportunity for co-founding in the study.This observation is irrelevant; the same conditions existed for both arms of the trial. 
Six of the seven studies were performed in a single institution making generalization problematic. Single-centre trials are not unusual, hence the usefulness of systematic reviews.

The Cochrane Review authors concluded was that there was some evidence that plastic adhesive incise drapes increase infection rates, but there is no such evidence. Five studies were included in the meta-analysis for clear incise drapes. The relative risk of surgical site infections was $1.23(95 \% \mathrm{Cl} 1.02-1.48)$ which is (barely) statistically significant. However, this purported risk traces to Cordtz et al. (1989), in which the authors specify that the rates of infection were "the same in draped patients and control." The Cochrane Collaboration's conclusion that adhesive drapes augment infection risk is supported by only a single study - from which even the authors did not conclude that risk was increased. Again, this is why systematic reviews are so useful, results from one trial are often inconclusive and trial authors can make statements which are not always supported by the data they present. Cochrane review authors are independent, they have no conflicts of interest and present the data and draw conclusions independently of any affiliations. In addition, a statistically significant $23 \%$ increase in risk of SSI in the plastic drape group seems to us to be clinically important and ignoring it would be indefensible.

\section{CONCLUSIONS}

The meta-analyses by Webster and Alghandi as published in the Cochrane Review is flawed and should not have been accepted. It fails to critically highlight the many shortcomings for the data, the absence of meaningful information, and the inability to determine the effect of incise drapes on surgical site infection rates.

\section{We do not agree with the assessment of the reviewers from 3 M. The review was carefully peer refereed and we are confident in its results.}

There is a compelling need to conduct further clinical studies to determine the effect of plastic adhesive incise drapes on surgical site infection rates.

We would be pleased to see published, independent, robust RCTs of plastic adhesive drapes to add to our review in future updates.

\section{Contributors}

Nancy Klinger, Manager, Clinical Affairs, 3M Infection Prevention Division (plus the authors of the Technical report)

Gill Worthy, Statistical Editor, Cochrane Wounds Group.

Martin Bland Professor of Health Statistics, University of York.

Joan Webster, Nursing Director, Research. Centre for Clinical Nursing. Royal Brisbane and Women's Hospital. Brisbane, Queensland

\section{HISTORY}

Protocol first published: Issue 1, 2007

Review first published: Issue 4, 2007

\begin{tabular}{|c|c|c|}
\hline Date & Event & Description \\
\hline 15 April 2015 & New search has been performed & Fourth update \\
\hline 15 April 2015 & $\begin{array}{l}\text { New citation required but conclusions } \\
\text { have not changed }\end{array}$ & $\begin{array}{l}\text { New search, no new studies included, one excluded study added } \\
\text { (Falk-Brynhildsen 2013a). Conclusions remain unchanged. }\end{array}$ \\
\hline 24 February 2015 & Amended & Contact details updated. \\
\hline 16 August 2013 & Feedback has been incorporated & $\begin{array}{l}\text { Response to feedback received from a representative of the As- } \\
\text { sociation of periOperative Registered Nurses (AORN) and from } \\
3 \mathrm{M} \text {, a manufacturer of plastic adhesive incise drapes. }\end{array}$ \\
\hline 25 July 2012 & New search has been performed & Third update. New search, no new studies identified \\
\hline 25 July 2012 & $\begin{array}{l}\text { New citation required but conclusions } \\
\text { have not changed }\end{array}$ & No change to conclusions \\
\hline 30 August 2011 & Amended & Contact details updated. \\
\hline 15 November 2010 & New search has been performed & $\begin{array}{l}\text { Second update, new search, one additional citation was exclud- } \\
\text { ed (Swenson 2008). No change to conclusions. . }\end{array}$ \\
\hline
\end{tabular}




\begin{tabular}{lll}
\hline Date & Event & Description \\
\hline 27 February 2009 & New search has been performed & $\begin{array}{l}\text { First update. New search (February 2009), no new citations were } \\
\text { identified. A study awaiting assessment (Breitner 1986) has been } \\
\text { assessed and excluded from the review. Risk of bias tables and } \\
\text { Summary of findings tables added. No change to conclusions. }\end{array}$ \\
\hline 8 May 2008 & Amended & Converted to new review format. \\
\hline 19 June 2007 & $\begin{array}{l}\text { New citation required and conclusions } \\
\text { have changed }\end{array}$ & Substantive amendment \\
\hline
\end{tabular}

\section{CONTRIBUTIONS OF AUTHORS}

JW co-wrote the protocol, the 'Results' and 'Discussion' sections of the review, and identified studies from the search, independently extracted data and judged the quality of studies. JW contacted the trial authors and drape manufacturers, performed the meta-analysis and wrote the 'Description of Studies', 'Methodological Quality' and 'Reviewers Conclusions' sections of the review, and constructed the 'Tables of Comparisons'. JW coordinated the review update, performed the writing and editing of the review update, completed the drafts of the update, made an intellectual contribution, performed previous work that was the foundation of the current update and wrote to study authors, experts and companies.

AA co-wrote the protocol, the 'Results' and 'Discussion' sections of the review, and identified studies from the search, independently extracted data and judged the quality of studies. AA also approved the review update prior to submission.

\section{Contributions of editorial base:}

Nicky Cullum: edited the review, advised on methodology, interpretation and review content. Approved the final review and first review update prior to submission.

Sally Bell-Syer: coordinated the editorial process. Advised on methodology, interpretation and content. Edited and the review and the updates of the review.

Rocio Rodriguez-Lopez: ran the searches for the update.

\section{DECLARATIONSOF INTEREST}

Joan Webster: none known.

Abdullah Alghamdi: none known.

\section{SOURCES OF SUPPORT}

\section{Internal sources}

- School of Nursing and Midwifery, Queensland University of Technology, Queensland, Australia.

- School of Nursing and Midwifery, Griffith University, Brisbane, Australia.

\section{External sources}

- NIHR/Department of Health (England), (Cochrane Wounds Group), UK.

\section{DIFFERENCES BETWEEN PROTOCOLAND REVIEW}

The only subgroup analysis that was possible, based on available data, was of clean compared with contaminated surgery. Nor was it possible to undertake a planned sensitivity analysis based on the type of material the drape was made from due to insufficient detail about the products.

\section{INDEX TERMS}

\section{Medical Subject Headings (MeSH)}

*Adhesives; *Plastics; lodine [therapeutic use]; Length of Stay; Randomized Controlled Trials as Topic; Surgical Drapes [ ${ }^{\star}$ adverse effects]; Surgical Wound Infection [*prevention \& control] 


\section{MeSH check words}

Humans 